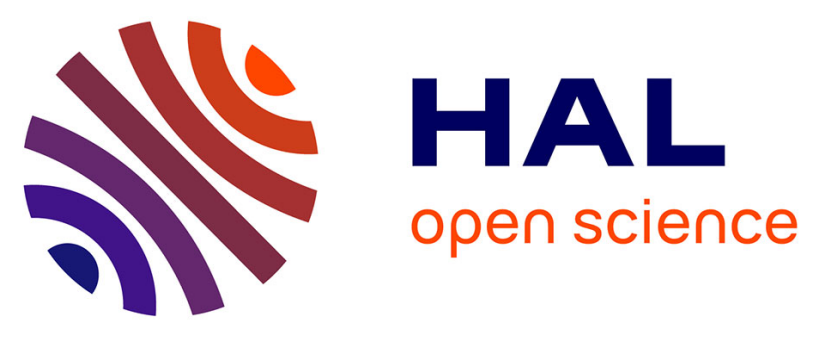

\title{
Analysis of the CodY RNome reveals RsaD as a stress-responsive riboregulator of overflow metabolism in Staphylococcus aureus
}

Yoann Augagneur, Alyssa N King, Noëlla Germain-Amiot, Mohamed Sassi, John W Fitzgerald, Gyan S Sahukhal, Mohamed O Elasri, Brice Felden, Shaun R Brinsmade

\section{To cite this version:}

Yoann Augagneur, Alyssa N King, Noëlla Germain-Amiot, Mohamed Sassi, John W Fitzgerald, et al.. Analysis of the CodY RNome reveals RsaD as a stress-responsive riboregulator of overflow metabolism in Staphylococcus aureus. Molecular Microbiology, 2020, 113 (2), pp.309-325. 10.1111/mmi.14418 . hal-02397672

\section{HAL Id: hal-02397672 \\ https://hal-univ-rennes1.archives-ouvertes.fr/hal-02397672}

Submitted on 11 Dec 2019

HAL is a multi-disciplinary open access archive for the deposit and dissemination of scientific research documents, whether they are published or not. The documents may come from teaching and research institutions in France or abroad, or from public or private research centers.
L'archive ouverte pluridisciplinaire HAL, est destinée au dépôt et à la diffusion de documents scientifiques de niveau recherche, publiés ou non, émanant des établissements d'enseignement et de recherche français ou étrangers, des laboratoires publics ou privés. 
DR. MOHAMED ELASRI (Orcid ID : 0000-0003-0312-2292)

PROF. SHAUN BRINSMADE (Orcid ID : 0000-0002-5381-2817)

Article type : Research Article

Analysis of the CodY RNome reveals RsaD as a stress-responsive riboregulator of overflow metabolism in Staphylococcus aureus

Yoann Augagneura*, Alyssa N. King ${ }^{b^{*}}$, Noëlla Germain-Amiota, Mohamed Sassia, John W.

Fitzgerald $^{\mathrm{b}}$, Gyan S. Sahukhalc, Mohamed O. Elasric, Brice Felden ${ }^{\mathrm{a}}$, and Shaun R. Brinsmade ${ }^{\mathrm{b} \#}$

*Should be considered joint first author; \#Should be considered joint senior author

INSERM U1230 Biochimie Pharmaceutique, Université de Rennes I, Rennes, Francea; Department of Biology, Georgetown University, Washington, DC USA ${ }^{\text {; }}$ Center of Molecular and Cellular Biosciences, The University of Southern Mississippi, Hattiesburg, MS USA

Running Title: RsaD-dependent regulation of metabolism in S. aureus

\#Address correspondence to Shaun R. Brinsmade, shaun.brinsamde@georgetown.edu or to Brice Felden, brice.felden@univ-rennes1.fr

Key words: sRNA, post-transcriptional, regulation, Gram-positive, staphylococci, physiology 


\section{Summary}

In Staphylococcus aureus, the transcription factor CodY modulates the expression of hundreds of genes, including most virulence factors, in response to the availability of key nutrients like GTP and branched-chain amino acids. Despite numerous studies examining how CodY controls gene expression directly or indirectly, virtually nothing is known about the extent to which CodY exerts its effect through small regulatory RNAs (sRNAs). Herein, we report the first set of sRNAs under the control of CodY. We reveal that staphylococcal sRNA RsaD is overexpressed $>20$-fold in a CodY-deficient strain in three $S$. aureus clinical isolates and in S. epidermidis. We validated CodY-dependent regulation of $r s a D$ and demonstrate that CodY directly represses $r s a D$ expression by binding the promoter. Using a combination of molecular techniques, we show that RsaD post-transcriptionally regulates alsS (acetolactate synthase) mRNA and enzyme levels. We further show that RsaD redirects carbon overflow metabolism, contributing to stationary phase cell death during exposure to weak acid stress. Taken together, our data delineate a role for CodY in controlling sRNA expression in a major human pathogen and indicate that RsaD may integrate nutrient depletion and other signals to mount a response to physiological stress experienced by $S$. aureus in diverse environments. 


\section{Introduction}

Staphylococcus aureus is a Gram-positive bacterium that exhibits great versatility in its ability to acclimate to a number of different ecological niches. Thus, the response to changing environments and physiological stress is critical for its survival (Graham et al., 2006). S. aureus can colonize virtually every surface of the host, and can persist on fomites and other surfaces external to the host (Mertz et al., 2007, Desai et al., 2011). Each of these niches varies with regards to the state of the environment, including oxygen or nutrient availability, $\mathrm{pH}$, temperature, osmolarity, and the presence of reactive oxygen species. The ability of $S$. aureus to rapidly and readily respond to cues indicating environmental stresses is rooted in its metabolic flexibility. $S$. aureus can employ a number of strategies to derive energy molecules and continue growth in distinct environments. At times when biosynthetic and metabolic pathways are unable to be utilized, $S$. aureus can turn on the expression of any of its virulence factors, including secreted proteases and digestive enzymes, to break down host tissue for nutrient extraction to continue growth and reproduction (Cheung et al., 2004, Olson et al., 2013, Ibberson et al., 2014). The S. aureus response is coordinated by regulatory factors, some of which act directly on target genes while others act indirectly by controlling the production and activity of other protein and RNA-based factors, which in turn control the target genes.

One of the many factors $S$. aureus has to respond to nutrient limitation is CodY, a global regulatory protein found in the majority of low $G+C$ Gram-positive bacteria (Sonenshein, 2005). CodY is a transcription factor that links bacterial physiology to pathogenesis by sensing nutrient availability and altering the expression of dozens of genes involved in metabolism as well as virulence (Brinsmade, 2016, Majerczyk et al., 2010, Pohl et al., 2009, Dineen et al., 2010, Malke et al., 2006, Bennett et al., 2007, Hendriksen et al., 2008, Lemos et al., 2008, Lobel et al., 2012, Château et al., 2011). When bound by its co-repressors GTP and/or branched-chain amino acids (isoleucine, leucine, valine [ILV]), CodY binds to sitespecific chromosomal sequences (AATTTTCWGAAAATT) originally identified in Lactococcus lactis and refined by Majerczyk et al. for S. aureus (Majerczyk et al., 2010, den 
Hengst et al., 2005). During times when these molecules are limited, CodY activity decreases and gene expression of CodY targets are altered to reconfigure the physiology of the cell to maintain growth and survival (Kaiser et al., 2018, King et al., 2018, Waters et al., 2016).

The role of transcription factors in regulating RNA-based factors has been widely studied in Gram-negative bacteria, and in particular, E. coli (Escolar et al., 1999, Masse \& Gottesman, 2002, Richards \& Vanderpool, 2011, Storz et al., 2011). However, in Gram-positive bacteria like $S$. aureus, regulatory RNAs are still an emerging field; only a relatively small number of the known sRNAs have established biological functions (Quereda \& Cossart, 2017, Mars et al., 2016, Guillet et al., 2013, Broach et al., 2016). For instance, RNAIII - the sRNA effector of the accessory gene regulator (Agr) quorum sensing system - adjusts toxin expression in response to population density via the regulation of many direct and indirect targets (Marroquin et al., 2019, Cheung et al., 2011, Queck et al., 2008, Boisset et al., 2007, Recsei et al., 1986, Novick et al., 1993, Balaban \& Novick, 1995). Other sRNAs in S. aureus have been discovered to mount responses to changing environmental conditions (Nielsen et al., 2011), prompt the synthesis of virulence-associated genes (Manna et al., 2018, Zapf et al., 2019, Romilly et al., 2014), influence antibiotic resistance (Eyraud et al., 2014), and adjust metabolism during growth (Bohn et al., 2010b, Geissmann et al., 2009). Employing the regulatory influence of sRNAs to adjust cellular physiology is advantageous. First, production of SRNAs is more energetically favorable compared to the production of protein factors; they are typically small in size and do not require the process of translation for function (Beisel \& Storz, 2010, Manna et al., 2018, Masse \& Gottesman, 2002). Additionally, sRNAs bring about a rapid and reversible response by acting at a step closer to protein production compared to transcription factors (Beisel \& Storz, 2010, Shimoni et al., 2007, Bohn et al., 2010a).

Coding gene targets of $S$. aureus CodY have been extensively studied (Majerczyk et al., 2010, Waters et al., 2016, King et al., 2018, Pohl et al., 2009), but virtually nothing is known 
about the regulatory relationship between CodY and sRNAs. To gain insight into CodY's relationship to sRNAs and how they may be used to coordinate adjustments to Grampositive physiology and pathogenicity, we performed RNA-sequencing analysis in three clinical isolates of $S$. aureus and screened for sRNAs that were differentially expressed in a $\Delta \operatorname{cod} Y$ mutant compared to its parent strain. In this study, we identified RsaD as a novel effector regulated by CodY. We biologically confirmed CodY-dependent regulation of RsaD in a variety of clinically relevant $S$. aureus isolates and in the coagulase negative Staphylococcus epidermidis. We show that $S$. aureus RsaD acts as a trans-acting sRNA to control the abundance of alsS mRNA and acetolactate synthase activity, thus contributing to cell death regulation in osteomyelitis isolate UAMS-1. 


\section{Results}

Transcriptomic analysis reveals novel sRNA CodY targets, including RsaD.

Previous work by us and others investigated the CodY regulon, but genome-wide annotations for sRNAs in S. aureus have only recently become available (Carroll et al., 2016, Sassi et al., 2015a). We aimed to probe further into the CodY regulon by specifically searching for regulatory RNAs under CodY control. To do this, we performed RNA-seq on cells grown in tryptic soy broth (TSB; a rich, complex medium) during exponential phase (see Experimental Procedures), a condition that maximizes CodY activity. We used three clinical isolates of $S$. aureus (Newman, UAMS-1, and USA300) and compared a wild-type (WT) strain to its corresponding $\operatorname{cod} Y$ null mutant $(\Delta \operatorname{cod} Y)$. We first generated sRNA annotation files based on the Staphylococcal Regulatory RNAs database (Sassi et al., 2015a). To study sRNA transcript variations between WT and $\Delta \operatorname{cod} Y$ mutant strains, we applied a cut-off of two when calling differential expression in DESeq (Anders \& Huber, 2010). Overall, there were 50 sRNAs significantly up- or downregulated, including 44, 21 , and 18 in Newman, USA300 and UAMS-1 strains, respectively (Fig 1, Table 1 and Supplementary Table 1). Most sRNAs were overexpressed, ranging from 2- to 700-fold upregulated in $\Delta \operatorname{cod} Y$ mutant cells, consistent with the known role for CodY as a repressor for coding gene targets (Pohl et al., 2009, Majerczyk et al., 2010, Waters et al., 2016). Analysis of overexpressed sRNAs indicated that 11 were regulated by CodY in all three clinical isolates (Fig 1). Of these, eight were originally described as cis-acting regulators, riboswitches or 5'UTRs (Beaume et al., 2010, Howden et al., 2013, Sassi et al., 2015a), and three were identified as trans-encoded RNAs (Abu-Qatouseh et al., 2010, Geissmann et al., 2009). Two putative trans-acting sRNAs, RsaD and Teg16, were over 100-fold up-regulated in $\triangle \operatorname{cod} Y$ mutants (Table S1A). We validated the RNA-seq data by measuring transcript abundance via quantitative real-time RT-PCR (qRT-PCR) on three targets (teg1, rsaOB, and srn_1020_sRNA90) that were up-regulated in all three isolates (Fig S1). Then, we focused on RsaD, which had previously been identified as a putative trans-acting staphylococcal sRNA containing a C-rich box that is characteristic of other regulatory RNAs (Geissmann et 
al., 2009, Boisset et al., 2007). Thus, we sought to further examine the genetic interaction between $r s a D$ and $\operatorname{cod} Y$.

The $r s a D$ gene (SARs050) is located in the intergenic region between an annotated nucleoside permease gene (SAR0655; nupC2) and a gene encoding a YitT protein family member (SAR0656) (Fig 2A). A putative CodY motif with no more than three mismatches relative to the consensus was identified in the $r s a D$ promoter upstream of the annotated transcription start of at least fifteen staphylococcal species, indicating that $r s a D$ is likely a conserved, direct CodY target in these bacteria (Fig 2B). To test the role of CodY in controlling expression of $r s a D$ in both $S$. aureus and $S$. epidermidis, a coagulase-negative staphylococcal bacterium that is commonly found as part of the skin microbiome (Rogers et al., 2009, Parlet et al., 2019), we performed qRT-PCR on WT and $\Delta c o d Y$ mutant cells during exponential growth in TSB. Under these conditions, CodY activity is maximized. In WT cells, we measured relatively few copies of normalized $r s a D$ transcript $(>1$ in $S$. aureus and $>0.1$ in S. epidermidis). In contrast, we observed that $r s a D$ transcript abundance increased 20fold and 200 -fold in S. aureus and S. epidermidis $\Delta \operatorname{cod} Y$ mutant cells, respectively (Fig 2C, compare black vs. blue bars).

To test the hypothesis that $\mathrm{CodY}$ directly regulates $r s a D$ expression by binding the identified motif in the $r s a D$ promoter, we performed an electrophoretic mobility shift assay (EMSA) with histidine-tagged S. aureus CodY protein ( $\mathrm{SaCodY}-\mathrm{His}_{6}$ ). We synthesized a 6carboxyfluorescein (6-FAM)-labeled DNA fragment containing the upstream regulatory region of $S$. aureus rsaD and the CodY motif ( $\mathrm{P}_{\text {rsaDWT }}$ ) (Fig 3A). In EMSAs, CodY:DNA complexes formed with as little as $6.3 \mathrm{nM}$ CodY (Fig S2A), and the dissociation constant $\left(\mathrm{K}_{\mathrm{D}}\right)$ was calculated to be $\sim 60 \mathrm{nM}$ CodY, indicating a moderate affinity of CodY for the $r s a D$ promoter, consistent with previously characterized CodY targets (Fig 3B)(Majerczyk et al., 2010). To further confirm that the interaction between CodY and $r s a D$ was authentic we performed an EMSA with a fragment of the po/C gene, transcribed independently of CodY, and observed no interaction under the same conditions (Fig S2B). 
We then determined the relevance of the CodY motif in vivo. Here, we introduced gfp transcriptional fusions into WT and $\Delta \operatorname{cod} Y$ mutant cells. One construct contained the WT $r s a D$ promoter fused to gfp ( $\left.\mathrm{P}_{r s a D W T}-g f p\right)$, while the other contained the $r s a D$ promoter in which the CodY motif was mutagenized to contain no more than 2 matches to the

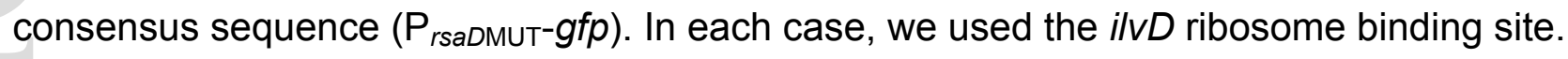
Because fusion-associated fluorescence was indistinguishable from background autofluorescence, we measured $g f p$ transcript using qRT-PCR as a proxy for promoter activity. In agreement with our results above, we found that CodY represses the wild-type

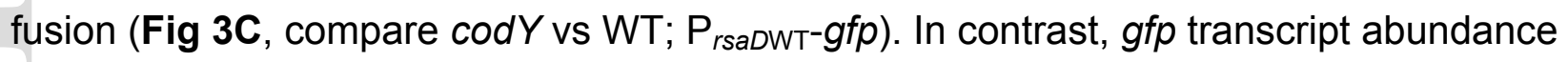
was essentially identical in WT and $\Delta \operatorname{cod} Y$ mutant cells carrying the mutagenized fusion. We observed no difference in cells harboring $\mathrm{P}_{\text {rsaDMUT-gfp compared to the } \Delta \operatorname{cod} Y \text { mutant }}$ carrying the WT fusion, indicating that CodY was no longer able to repress the mutagenized fusion (Fig 3C). Further, we tested whether CodY binds $P_{r s a D}$ in living cells using ChIP-PCR (Batte et al., 2018). In S. aureus strains LAC (USA300 CA-MRSA) and UAMS-1 (USA200 MSSA), we measured 20- to 200-fold enrichment of a DNA fragment containing the $r s a D$ promoter region during exponential phase in $\Delta \operatorname{cod} Y$ mutant cells expressing a wild-type copy of $\operatorname{cod} Y$ in trans. As expected, we did not detect appreciable enrichment in the absence of CodY (Fig 3D). Taken together, these data indicate that CodY directly represses $r s a D$ expression during laboratory growth in rich, complex medium by binding a region containing the CodY motif. Notably, this is the first described role for CodY in strongly repressing an SRNA target in any bacterium.

RsaD directly regulates alsS, a positively regulated $\mathrm{Cod} Y$ target that has a role in carbon utilization.

Up to this point, we have shown that RsaD is produced by two staphylococcal species and is repressed by CodY during laboratory culture. However, the function of most sRNAs, including RsaD, are unknown. An in silico search for targets of RsaD conducted with RNA predator and intaRNA (Eggenhofer et al., 2011, Kery et al., 2014, Mann et al., 2017, Wright 
et al., 2014, Busch et al., 2008) revealed that alsS mRNA is among the strongest potential interacting partners (Table S1B). The IntaRNA (Busch et al., 2008, Mann et al., 2017, Wright et al., 2014, Raden et al., 2018) analysis predicts that nucleotides 127 to 167 of RsaD bind to the 5'UTR of the alsS mRNA including its ribosome binding site (Fig S3A). This domain of RsaD contains a UCCC motif that has predicted complementarity to the RBS of alsS mRNA suggesting that RsaD may post-transcriptionally regulate alsS.

To investigate the regulation between $\mathrm{RsaD}$ and alsS, we mixed a fragment of radiolabeled alsS (from predicted transcriptional start site +1 to nucleotide +340 ) with increasing amounts of the WT form of RsaD and conducted EMSAs (Fig 4A). Both RNAs form a complex in vitro. The specificity of the complex was assessed by adding a 50 -fold excess of either unlabelled alsS or SprA2 RNA (Germain-Amiot et al., 2019). The in silico analysis predicted that the interaction region of RsaD is downstream of nucleotide 127 (Fig S3). Thus, we generated a truncated version of RsaD composed of nucleotides 1-126, which resulted in complete loss of binding with alsS mRNA (Fig S4). To evaluate the requirement of one or more regions of RsaD for interaction with alsS, we generated two RsaD mutant constructs. One RsaD mutant allele replaces nucleotides 127-139 (ribosome binding site [RBS] interaction region of RsaD) with the corresponding nucleotides of alsS ( $\left.\operatorname{RsaD}_{127-141}\right)$ (Fig S3B). The other RsaD mutant allele replaced nucleotides 151-165 (accessory interaction region of RsaD) with the corresponding nucleotides of alsS (RsaD ${ }_{151-165)}$ (Fig S3C). Substitutions made to the RBS interaction region of RsaD resulted in the loss of interaction (Fig 4B); however, mutating the RsaD accessory region did not affect binding in vitro (Fig 4C). These results indicated that RsaD is able to bind als $S$ mRNA in vitro and that the RBS interaction region of $\mathrm{RsaD}$ is necessary for binding.

In a parallel set of experiments, we de-coupled RsaD and alsS from their native regulation to test their interaction in living cells. We fused the alsS regulatory region, including the predicted interaction regions, the ribosome binding site (RBS), and the first 11 codons of alsS coding sequence in-frame to GFP and expressed this plasmid-borne construct using 
the constitutive tufA promoter $\left(\mathrm{P}_{\text {tufA-als }}\right.$-affp) in the S. aureus laboratory strain RN4220. We then introduced a second compatible plasmid expressing wild-type $r s a D$ under the control of the same tufA promoter $\left(\mathrm{P}_{\text {tufA }}-r s a D\right)$ to ensure stoichiometric amounts of RsaD and alsS. Using flow cytometry, we measured GFP fluorescence during exponential growth and measured a 2.5-fold reduction in GFP fusion fluorescence in the strain containing $\mathrm{P}_{\text {tufa-alsS- }}$ gfp and $\mathrm{P}_{\text {tufA }}-r s a D$ compared to a strain expressing $\mathrm{P}_{\text {tufA }}-$ alsS-gfp but not $\mathrm{P}_{\text {tufA }}-r s a D$ (Fig 4D). We then tested the necessity of the identified interaction sites of RsaD in vivo. When both the RBS interaction region and the accessory interaction region of RsaD were mutated, GFP signal remained at levels essentially identical to those measured in the strain with only the vector (Fig 4D). The lack of interaction between RsaD and alsS mRNA was not due to reduced RsaD RNA abundance (Fig S5). To further confirm specificity for the RsaD-alsS

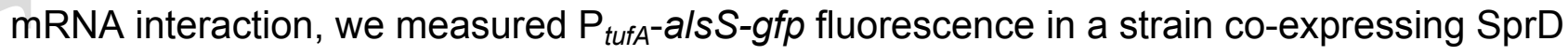
(Ivain et al., 2017), a sRNA not predicted to regulate alsS. As seen in Fig S6, we saw no difference in GFP levels in the presence of SprD.

The downregulation of the alsS-gfp translational fusion suggests that RsaD acts to destabilize alsS transcript, block translation by preventing ribosome loading, or both. To address the latter possibility, we pursued toeprint assays. We first evaluated the effect WT and mutant versions of RsaD (Fig S3) on primer extension onto the alsS transcript in the absence of ribosomes (Fig 5, lanes 5-9). Only RsaD and $\mathrm{RsaD}_{127-139}$ led to potential structural changes resulting in modifications of the alsS profile (Fig 5, lanes 6 and 7). Then, we used purified $E$. coli ribosomes to form the translation initiation complex in the presence of the initiator tRNA ${ }^{f M e t}$. A significant toeprint signal was obtained indicating that ribosome could load onto alsS RNA (Fig 5, lane 10). We then tested whether WT RsaD could prevent ribosomal loading. Increasing the amount of RsaD resulted in the dose-dependent decrease of the toeprint signal, indicating RsaD could compete with the ribosome (Fig 5, lanes 11-13). Similarly, increasing quantities of $\mathrm{RsaD}_{151-165}$ led to a disappearance of the toeprint (Fig 5, lane 15-16), indicating that $\operatorname{RsaD}_{151-165}$ still has the ability to bind als $S$ mRNA and prevent translation initiation. This phenotype was similar to what we observed with the RNA:RNA 
EMSAs with regards to $\operatorname{RsaD}_{151-165}$. Conversely, both $\operatorname{RsaD}_{1-126}$ and $\operatorname{RsaD}_{127-139}$ could not inhibit ribosomal loading of alsS (Fig 5, lanes 17-18), consistent to what we observed with the EMSAs. These data suggest that RsaD regulates the expression of alsS, at least at the translational level, and binds target mRNA at the RBS to prevent ribosomal loading.

Consistent with known roles for CodY in redirecting carbon use through major metabolic intersections in Firmicutes, the alsSD genes are positively regulated by CodY (Waters et al., 2016). The alsSD operon (SAR2297 and SAR2296, respectively) encodes for acetolactate synthase and decarboxylase, the enzymes responsible for the conversion of pyruvate to acetoin. However, the mechanism by which this regulation occurs is unknown as neither the alsSD regulatory region nor the coding sequences contain an obvious CodY motif. Further, a binding site was not identified in a genome-wide pulldown experiment (Majerczyk et al., 2010). Given CodY's role in repressing rsaD and RsaD's ability to antagonize an alsS-gfp translational fusion, we wondered whether CodY's apparent positive regulation of alsSD could be explained by RsaD (Fig 6A). If so, then we would predict that knocking out $r s a D$ would eliminate the effect of $\mathrm{CodY}$ on als $S$ transcription. We generated a $\Delta \operatorname{cod} Y \Delta r s a D$ double mutant and measured alsS transcript abundance using qRT-PCR. We measured 3-fold higher alsS transcript in WT UAMS-1 relative to transcript measured in $\Delta \operatorname{cod} Y$ mutant cells (Fig 6B). In contrast, alsS transcript abundance was essentially unchanged in the $\Delta \operatorname{cod} Y \Delta r s a D$ double mutant (compare $\operatorname{cod} Y$ rsaD vs. $\operatorname{cod} Y$ ). To further delineate the effect of RsaD on AlsSD protein levels, we monitored the conversion of pyruvate to acetoin in cell-free extracts. Similar to transcript levels, AlsSD activity was reduced $\sim 3$-fold in the $\Delta \operatorname{cod} Y$ mutant but not in the $\Delta \operatorname{cod} Y \Delta r s a D$ double mutant (Fig 6C). As expected, because CodY tightly represses $r s a D$ expression, we observed no changes in alsS transcript abundance or AlsSD activity in the $\Delta r s a D$ mutant (Fig 6BC, compare $r s a D$ and WT). Altogether, these data indicate that RsaD and alsS mRNA interact specifically; both the RBS region and accessory region contribute equally. We show that RsaD acts to post-transcriptionally regulate als $S$ by blocking translation initiation. Further, we provide data suggesting that RsaD reduces transcript abundance potentially by destabilizing the alsS 
mRNA (Fig 6B). Notably, our results delineate a novel mechanism by which CodY controls the activity of a major carbon overflow pathway in S. aureus.

$R s a D$ regulates cell death in S. aureus isolate UAMS-1 under weak acid stress.

Previous work demonstrated that $S$. aureus experiences substantial cell death after aerobic growth in tryptic soy broth containing excess glucose (Thomas et al., 2014, Rice et al., 2007). This high glycolytic flux results in increased acetate production from pyruvate, catalyzed by the CidC pyruvate:menaquinone oxidoreductase enzyme (Zhang et al., 2017, Thomas et al., 2014). This acetate is secreted and lowers the $\mathrm{pH}$ of the medium, soon reaching the pKa of acetic acid $(\mathrm{pH} 4.8)$. Acetate is then protonated to form acetic acid, which can re-enter the cell. This phenomenon can yield a futile cycle in which dissociation of acetic acid and accumulation of protons in cytoplasm can cause cell death (Russell, 1991). The reactions of AlsSD (acetolactate synthase / decarboxylase) generate acetoin from pyruvate, consume protons, and is thus an acid resistance mechanism (Thomas et al., 2014, Rice et al., 2007). In S. aureus, RsaD abundance increases during stationary phase, an event that depends on the alternative stress sigma factor B (SigB) (Geissmann et al., 2009). SigB is also activated by a range of environmental stresses, including weak acid stress (King et al., 2018, Pané-Farré et al., 2009). Therefore, we investigated whether RsaD regulated cell death by redirecting carbon flow. First, we confirmed that there were no growth defects in WT UAMS-1 when excess glucose was added (35 mM) during the first hours of growth compared to standard TSB medium (14 mM glucose) (data not shown). Differences could be observed only after 7 hours with an earlier growth arrest when subjected to glucose supplementation. We measured $r s a D$ expression under those same conditions and observed an increase in expression around 4 hours of growth in TSB with $35 \mathrm{mM}$ glucose as the cells exited exponential phase (Fig 7A). Then, RsaD transcript level decreased from 5 hours to 9 hours, corresponding to entry into stationary phase. Similar results were obtained during growth in standard TSB, except we detected a second pulse of expression after 6 and 7 hours (Fig 7A). We measured RsaD production further into stationary phase and confirmed that RsaD was expressed in stationary phase in both standard TSB and TSB 
containing excess glucose even though relative quantification could not be achieved due to internal control transcript level variations (Fig 7B).

To determine the extent to which the $\Delta r s a D$ mutant is altered in cell death regulation, we performed an aerobic growth assay with UAMS-1 (WT) and the $\Delta r s a D$ mutant over a fiveday period. A sigB null mutant was included as a negative control as it is required for cidBC expression and exhibits increased stationary phase survival during weak acid exposure (Chaudhari et al., 2016). During aerobic growth in standard TSB, we measured no significant difference in cell survival when the $\Delta r s a D$ mutant and WT were compared, and there was no difference in the $\mathrm{pH}$ of culture supernatants (Fig 8A, C, compare black circles and asterisks). Glucose was consumed after one day of growth in this medium and the same medium supplemented with $35 \mathrm{mM}$ glucose (Fig S7). However, while UAMS-1 WT cells showed a substantial decrease in cell viability in stationary phase (Figs S8A, 8B) during aerobic growth in TSB with $35 \mathrm{mM}$ glucose concomitant with a drastic drop in culture $\mathrm{pH}$, we found that the $\Delta r s a D$ mutant exhibited increased viability compared to UAMS-1 after two days of growth ( $4 \%$ survival vs $>50 \%$ survival at day 2 ); this phenotype was complemented by integrating a wild-type copy of $r s a D$ under the control of its native promoter into the chromosome at the $\Phi 11$ att site (Figs 8B, 8D, 9A). After five days, $\Delta r s a D$ mutant cells exhibited the same loss in viability as UAMS-1 cells, indicating that $\Delta r s a D$ mutants experience a delay in cell death. In agreement with previous results, the $\triangle \operatorname{sig} B$ mutant survived reasonably well in TSB regardless of glucose concentration (Fig 8A-B). Whereas the $\mathrm{pH}$ of $\triangle s i g B$ culture supernatants increased over time, as expected based on previous reports (Thomas et al., 2014), it is notable that we did not measure a difference in $\mathrm{pH}$ in $\Delta r s a D$ culture supernatants (Figs 8D, 9B). This may simply be an issue of sensitivity in the assay.

Because acetate potentiates cell death and RsaD downregulates AlsSD-catalyzed acetoin synthesis, we speculated that $\Delta r s a D$ mutant cells excrete less acetate and more acetoin into the culture medium. To test this hypothesis, we measured acetate and acetoin levels. After 
two days of growth when the cell death phenotype is the strongest, we measured significantly more acetate in WT culture supernatants compared to $\Delta r s a D$ and $\Delta s i g B$ culture supernatants (Fig 8E). This was not due to lack of secretion, as all strains secreted acetate, and both the $\Delta r s a D$ mutant and the $\triangle s i g B$ mutant consumed acetate (Fig S8). Acetoin, a neutral metabolite, does not alter the $\mathrm{pH}$ and therefore can counter cell death. Conversely, we measured significantly higher levels of acetoin in $\Delta r s a D$ and $\Delta s i g B$ culture supernatants compared to that measured in WT culture supernatants (Fig 8F). Again, $\Delta r s a D$ mutant excretion phenotypes could be complemented genetically (Figs 9C-D). Taken together, our data indicate that RsaD contributes to cell death during aerobic growth and high glycolytic flux likely by shifting carbon toward acetate production. In the absence of RsaD, alsSD is derepressed and AlsSD enzymes are produced. 


\section{Discussion}

S. aureus continues to be a recalcitrant human pathogen in both the healthcare arena and within the community. Equipped with a multitude of metabolic and biosynthetic pathways as well as secreted virulence factors, $S$. aureus can adapt to essentially every environment to colonize or invade host tissues. Here, we sought to expand knowledge of the CodY regulon to include SRNAs in addition to the well-characterized genes under CodY control (Fig 1, Table 1, Table S1A). Previously, it was unknown whether CodY exerted regulatory effects on sRNAs beyond RNAIII, the effector molecule of the agr locus (Novick et al., 1993, Majerczyk et al., 2010). We demonstrate that RsaD is repressed by CodY and serves as a novel effector, responsible for the apparent positive CodY regulation of the alsSD genes by decreasing AlsSD enzyme activity and likely alsS transcript abundance (Figs 2, 3, 5, 6). Moreover, we show that this post-transcriptional regulation causes important changes to $S$. aureus physiology by redirecting carbon flow at a critical metabolic node. In this manner, RsaD contributes to $S$. aureus death in laboratory cultures by altering the balance of acetate and acetoin excretion (Fig 8) (Thomas et al., 2014).

RsaD's regulatory role in carbon overflow metabolism and cell death.

Prior to this study, RsaD's putative function as a regulatory RNA was based on sequence and prediction alone. Using toe-printing assays and in vivo system co-expressing $r s a D$ and alsS from plasmids, we demonstrate that RsaD is a trans-acting sRNA that regulates at least one mRNA target, alsS (Figs 4-6). RNA:RNA EMSAs between alsS and RsaD ${ }_{151-165}$ do not show loss of RsaD binding to als $S$ mRNA, whereas the interaction is lost with $\operatorname{RsaD}_{127-139}$ (Fig 4BC), suggesting that the RBS region of RsaD is more vital to RsaD's regulatory function. Our reporter assays, however, indicate that the accessory site of RsaD (nucleotides 151-165, see Fig S3) also contributes to regulation of alsS mRNA in vivo (Fig 4D). It is important to note that in vitro EMSAs are performed in a defined and somewhat artificial system where only the target mRNA and sRNA of interest are added to the reaction mixture, thus, there is no direct competition for RsaD to bind other mRNA targets. Moreover, the in vitro, simplified system is absent of ribosomes and other regulatory molecules that 
could potentially compete with RsaD for binding of alsS mRNA. This could be a situation where the site is required for regulation but not for binding. Interestingly, upon further inspection of the alsS transcript, we identified a third site of potential RsaD-alsS complementarity further downstream of the ribosome binding site than the 11 codons

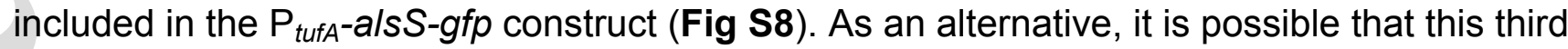
site on the alsS mRNA may interact with RsaD in growing cells to block translation, though the spacing and free energy of formation of the RsaD-alsS duplex mediated by this site are not as favorable as the ribosome binding site and accessory site. Further experiments are needed to determine the exact role of this additional site in RsaD-alsS interactions.

In the present study, we identified a function for RsaD with regards to $S$. aureus cell death. After two days of growth, $\Delta r s a D$ mutant cells exhibit increased cell survival compared ot WT cells. However, following two days of growth, cell survival of the $\Delta r s a D$ mutant drops towards WT levels (Fig 8B), indicating that RsaD is not the only factor necessary for the observed cell death phenotype. This delay in cell death is not surprising, given the known role of SigB in cell death (Chaudhari et al., 2016) and how SigB induces rsaD expression (Geissmann et al., 2009). SigB activation is transient (Pané-Farré et al., 2009), thus it is possible that RsaD controls this phenotype in early stationary phase, but that there are other functionally redundant factor(s). Further, we did not observe the expected $\mathrm{pH}$ change in $\Delta r s a D$ cultures at day two (Fig 8D). Based on how closely the $\Delta r s a D$ metabolite profile and percent cell survival at day two phenocopy the $\Delta s i g B$, we were expecting the $\mathrm{pH}$ of the $r s a D$ mutant to increase (Fig 8B, EF). It is possible that RsaD regulates the production of a yet-to-be discovered secreted metabolite that masks the reduced production of acetate.

RsaD integrates multiple signals into staphylococcal regulatory networks.

Multiple pieces of evidence suggest that RsaD is a converging point for multiple global regulators in S. aureus, potentially expanding the role of RsaD for responding to a variety of stress signals that the bacterium faces in its ever-changing environment. This guides our working model, as shown in Figure 10. First, we identified CodY as a direct repressor of 
$r s a D$ expression (Fig 3). Second, others have shown that $r s a D$ is dependent on Sigma B (Geissmann et al., 2009), the alternative sigma factor responsible for activating the general stress response in $S$. aureus, as well as playing critical roles in virulence and persistence (Chaturongakul et al., 2008, Novick, 2003, Tuchscherr et al., 2015, Mitchell et al., 2013, Hecker et al., 2007). How SigB controls $r s a D$ expression, whether by directly binding to the $r s a D$ promoter or through an indirect method, requires further study since there exists a lack of understanding SigB activation in S. aureus compared to related Firmicute Bacillus subtilis (Pané-Farré et al., 2009). Third, a recent study demonstrated activation of RsaD upon exposure to nitric oxide (NO), likely dependent on the SrrAB two-component system (TCS) (Bronesky et al., 2019). SrrAB is a regulatory system important for the expression of virulence factors, including ones important for biofilm formation and even programmed cell lysis. The current thought is that reduced respiration due to NO exposure or other stresses results in the accumulation of reduced menaquinone and triggers SrrAB activity (Mashruwala \& Boyd, 2017, Mashruwala et al., 2017). Another recent study examined global changes in transcript abundance in an $\Delta a g r$ mutant and measured an increase in $r s a D$ expression (Marroquin et al., 2019), indicating that RsaD production is controlled by population density. The mechanisms by which this integration is achieved remain unexplored but are a current focus of our lab. For instance, a conserved SrrA motif was identified in the $r s a D$ promoter (Bronesky et al., 2019). As for repression by the Agr system, the primary output is RNAlll production, and it is conceivable that RNAlll may bind and sequester RsaD, similar to other sRNAs that act as a molecular sponge (Miyakoshi et al., 2015). Alternatively, AgrA could potentially repress $r s a D$ expression, although AgrA typically behaves as an activator and has been shown to stimulate expression of the agr $\mathrm{P} 2$ promoter for the agrBDCA operon as well as the genes coding for the $\alpha$ - and $\beta$-phenol-soluble modulins (PSMs) (Queck et al., 2008, Kavanaugh \& Horswill, 2016). Experiments are underway to investigate Agr regulation of RsaD and the impact of RsaD during infection. 


\section{Experimental Procedures}

Bacterial Strains, Growth Media, and Culture Conditions.

All strains constructed during this study are isogenic derivatives of $S$. aureus or $S$. epidermidis; all strains are listed in Table S2A. Cultures of S. aureus and S. epidermidis were grown in tryptic soy broth containing dextrose $\left(2.5 \mathrm{~g} \mathrm{~L}^{-1}\right)$ (BD Biosciences) unless otherwise indicated. E. coli cultures were grown in Lennox (L) medium (Lennox, 1955) lacking glucose. When necessary, media were solidified with agar at $1.5 \%[\mathrm{w} / \mathrm{v}]$ and antibiotics were supplemented at the following concentrations: ampicillin, $50 \mathrm{\mu g} \mathrm{ml}^{-1}$; erythromycin, $5 \mathrm{\mu g} \mathrm{ml}^{-1}$; chloramphenicol, $10 \mathrm{\mu g} \mathrm{ml}^{-1}$; tetracycline, $3 \mathrm{\mu g} \mathrm{ml}^{-1}$. Unless otherwise indicated, experiments were initiated by inoculating overnight cultures (preadapted to the experimental medium; incubated at $37^{\circ} \mathrm{C}$ with rotation) to a starting optical density of 0.05 at $600 \mathrm{~nm}\left(\mathrm{OD}_{600}\right)$ in $125 \mathrm{ml}$ DeLong shake flasks filled with $25 \mathrm{ml}$ of TSB containing $14 \mathrm{mM}$ glucose (5:1 flask-to-medium ratio). Pre-cultures were incubated at $37^{\circ} \mathrm{C}$ in a water bath with constant aeration $(280 \mathrm{rpm})$ to an $\mathrm{OD}_{600}$ of $\sim 1$, at which time cells were re-diluted into fresh medium to a starting $\mathrm{OD}_{600}$ of 0.05 . Growth was monitored as increase in $\mathrm{OD}_{600}$ using a Beckman Coulter DU350 or Amersham Ultraspec 2100 pro UV-visible spectrophotometer.

\section{Genetic Techniques.}

Oligonucleotides used in this study were synthesized by Integrated DNA Technologies (IDT; Coralville, IA or Leuven, Belgium) and are listed in Table S2B. All plasmids and chromosomal alleles were verified by Sanger Sequencing performed by GeneWiz (Germantown, MD). Plasmids were introduced in S. aureus strain RN4220 by electroporation as previously described (Schenk \& Laddaga, 1992). Plasmids and marked mutations were moved between $S$. aureus strains via $\Phi_{11}$-mediated transduction (Novick, 1991).

\section{Plasmid Constructions}


(i) Construction of gfp reporter plasmids. To create the rsaD-gfp transcriptional fusion, a 131nucleotide (nt) fragment containing the promoter and ilvD ribosome binding site (RBS) flanked with Sphl and Smal restriction sites was synthesized as a gene block by IDT. The fragment was cut with Sphl and Smal and ligated to the same sites of pDM4 (Moormeier et al., 2013) to generate pSRB106 (the divergently transcribed cidABC-IrgAB promoter regions were released). To generate the mutant fusion, a new fragment was synthesized with the sequence of the CodY binding motif replaced by random sequence and ligated to pUC57kan. This construct, prepared by GenScript (Piscataay, NJ) was named pAK006. pAK006 was then digested with Sphl and Smal to release the mutant $r s a D$ promoter fragment. The WT $r s a D$ promoter fragment from pSRB106 was then replaced with this new mutant fragment using the same enzymes, generating pAK007.

(ii) Construction of rsaD deletion and complementation plasmids. DNA fragments flanking the $r s a D$ gene were synthesized by PCR using oAK026 and oAK027 for the upstream region and OAK029, and oAK093 for the downstream region. Fragments were mixed in equal proportions for use in an overlap PCR (Vallejo et al., 2008) using oligonucleotides oAK026 and OAK093. The resulting fragment contained EcoRI and Sall sites, which were ligated to the same sites of pJB38 (Bose et al., 2013) to yield pAK015. pAK015 was moved into $S$. aureus strain UAMS-1 and the clean deletion of $r s a D$ was generated using allelic exchange as previously described (Bose, 2014). The mutant was verified by PCR and Sanger sequencing.

For complementation studies, a DNA fragment containing the $r s a D$ promoter and nucleotides 1-177 of the annotated sequence (Sassi et al., 2015a) was generated by PCR using oAK102 and OAK103. The resulting fragment contained Sall and BamHI restriction sites, which were used to digest the DNA. The digested fragment was ligated to the same sites of pLL39 (Luong \& Lee, 2007) to yield pAK019. pAK019 was then introduced into RN4220 cells carrying pLL2787 to facilitate integration at the $\phi 11$ attachment site. Following 
PCR verification, the integrated construct was transferred to the indicated strains by transduction.

(iii) Construction sRNA-mRNA interaction plasmids. Plasmids to test sRNA-mRNA interaction plasmids were designed as described in Ivain et al. (Ivain et al., 2017). Gene fragments used to make the sRNA and mRNA interaction plasmids were ordered from IDT. Fragments contained the constitutive $S$. aureus tufA promoter fused to the gene or allele of interest. One fragment consisted of $\mathrm{P}_{\text {tufA }}$ fused to the als $S$ ' regulatory region (49 nucleotides upstream of the initiation codon) containing the putative $r s a D$ interaction region, the als $S$ ribosome binding site, and the first 11 codons of the als $S$ coding sequence $\left(\mathrm{P}_{\text {tufA- }}\right.$ alsS). The fragment was flanked with EcoRV and Sphl restriction sites. This fragment was

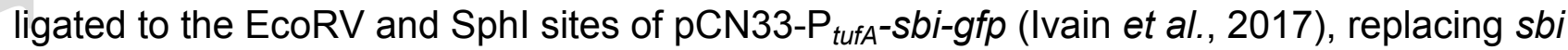
and generating a translational fusion construct named pAK010 ( $\left.\mathrm{P}_{\text {tufa }}-a / s S-g f p\right)$. The other gene fragments consisted of the promoter of tufA fused to the $r s a D$ sequence in its WT form $\left(\mathrm{P}_{\text {tufA }}-r s a D_{\mathrm{WT}}\right)$ as well as two mutant $r s a D$ alleles. $\mathrm{RsaD}_{127-139}$, the RBS binding site mutant, replaces nts 127-139 with the corresponding alsS sequence (Fig S3B). $\operatorname{RsaD}_{151-165}$, the accessory site mutant, replaces nts 151-165 with the corresponding als $S$ sequence. Both were designed as previously described (Ivain et al., 2017). All three $\mathrm{P}_{\text {tufa }}-r s a D$ fragments were digested with EcoRI and Sphl and then ligated to the same sites of pICS3 (Ivain et al., 2017). This resulted in pAK011, pAK018, and pAK017, respectively.

RNA extraction and quantitative, real-time Reverse Transcriptase (RT)-PCR. To collect RNA, 1-, 2-, or 4-ml samples of culture were mixed with an equal volume of ice-cold ethanol/acetate (1:1), frozen immediately on dry ice, and then stored at $-80^{\circ} \mathrm{C}$ until use. Cells were harvested by centrifugation for $5 \mathrm{~min}$ at $2000 \times \mathrm{g}$. Pellets were washed with TrisEDTA buffer (TE, pH 8.0) and resuspended in Trizol, equivalent to the original volume sampled. Samples were incubated at room temperature for $5 \mathrm{~min}$ before freezing at $-80^{\circ} \mathrm{C}$. Cells were mechanically disrupted with $\sim 100 \mu \mathrm{l} 0.1 \mathrm{~mm}$ zirconia/silica beads in a Precellys 24 homogenizer (Bertin Technologies) ( $3 \times 30 \mathrm{sec}$ pulses at $6800 \mathrm{rpm}$ with a $1 \mathrm{~min}$ 
incubation on ice in between pulses). Samples were centrifuged at maximum speed for 1 min in a microcentrifuge, and clarified extracts were mixed with an equivalent volume of $100 \%$ [v/v] ethanol. RNA was purified using a Direct-zol RNA Miniprep kit (Zymo Research) according to the manufacturer's instructions. To remove contaminating genomic DNA, $3 \mu \mathrm{g}$ of each RNA sample were treated with the Turbo DNA-free kit (Ambion) according to the manufacturer's instructions. cDNAs were synthesized from $250 \mathrm{ng}$ of RNA using the SensiFAST cDNA synthesis kit according to manufacturer's instructions. Quantitative PCR was performed using a C1000 Touch thermal cycler fitted with a CFX96 detection module and SsoAdvanced Universal SYBR Green Supermix (BioRad). Target-specific oligonucleotides (see Table S3) were used at $400 \mathrm{nM}$ each. Reaction mixtures were incubated at $98^{\circ} \mathrm{C}$ for 2 min followed by thermal cycling between $98^{\circ} \mathrm{C}$ and $65^{\circ} \mathrm{C}$. No template and no RT controls were run on each plate for each assay, and specificity of amplification products was verified using dissociation curve analysis. To obtain normalized transcript numbers, standard curves were generated for each primer set using serial dilutions of chromosomal DNA spanning at least five orders of magnitude. All reactions proceeded with $90 \%$ to $110 \%$ efficiency, and data points lay within linear regression with correlation coefficients ( $r^{2}$ values) $>98 \%$. qPCR data in $S$. aureus are presented as copies of target transcript relative to copies of polC transcript because expression varied $<2$-fold for all strains and conditions. qPCR data in S. epidermidis are presented as copies of target transcript relative to gyrA transcript because expression varied $<2$-fold for all strains and conditions.

\section{Transcriptomic analysis with RNA-seq and associated analyses. RNA-seq was} performed on three independent biological replicates for each strain and condition. A $20 \mu \mathrm{g}$ sample of nucleic acid prepared as described above was depleted of contaminating DNA using DNase I Amplification Grade (Invitrogen) following the recommendations of the manufacturer, excluding the addition of EDTA. RNA was precipitated in 100\% [v/v] ethanol with $0.1 \mathrm{vol} 3 \mathrm{M}$ sodium acetate $\mathrm{pH} 5.2$ and 1/50 glycogen. RNA pellets were washed twice with $70 \%$ ethanol, air dried and then resuspended in $25 \mu \mathrm{l}$ of DNase/RNase free water. The 
efficacy of DNase treatment was assayed by qPCR using primers for rpoC. Total DNAdepleted RNAs (samples that did not show amplification after 25 cycles) were then depleted of rRNA using the Ribo-Zero kit for Gram-positive bacteria (Epicentre). The efficacy of rRNA depletion and RNA integrity was assessed using an RNA 6000 Pico chip in a 2100 Bioanalyzer (Agilent). Only RNA samples with an RNA integrity Number (RIN score) of $\geq 8.0$ was used for subsequent analysis. Samples containing $<3 \%$ each of 16 s and 23 s rRNA were used to construct RNA-seq libraries using the NEBNext Ultra directional library kit for Illumina (NEB) according to the manufacturer's instructions, except the samples were initially incubated at $65^{\circ} \mathrm{C}$ for $5 \mathrm{~min}$ instead of $94^{\circ} \mathrm{C}$ for $15 \mathrm{~min}$. Double-stranded cDNA was purified using 1.8X AMPure XP beads (Agencourt) and adaptors were ligated. Libraries were then sequenced using an Illumina HiSeq 2500 instrument in high output mode (200 cycles).

RNA-Seq analysis pipeline.

sRNA annotation files in GFF format were prepared for Newman, USA300 and UAMS-1 strains using their corresponding genome sequences (Baba et al., 2008, Diep et al., 2006, Sassi et al., 2015b) and the SRD (Sassi et al., 2015a). Then, sRNA GFFs were added to current annotation files obtained from $\mathrm{NCBI}$ as described. Quality control of reads was done as previously described (Sassi el al 2015) but then trimmed to 50 nucleotides using trimmomatic (Bolger et al., 2014) to improve sRNA read mapping. Then, RNA-seq analysis was performed using DESeq as previously described (Bronsard et al., 2017) with some modifications. Briefly, to discard weakly expressed sRNAs, transcripts with mean HTSeq counts lower than 10 in both WT and mutants were removed from the analysis.

Expression and purification of recombinant proteins.

CodY was overproduced and purified as previously described (Mlynek et al., 2018, Kaiser et al., 2018). Protein concentration was quantified using a Pierce Coomassie protein assay kit according to the manufacturer's instructions.

DNA:protein Electrophoretic mobility shift assays (EMSAs). 
A DNA fragment containing the WT $r s a D$ promoter was synthesized by PCR using primers oAK014 and oSRB457 using genomic DNA from UAMS-1 to incorporate a 5' 6-FAM label. The po/C fragment was synthesized by PCR using primers oAK067 and oAK068 to incorporate a 5' 6-FAM label. EMSAs were performed with purified recombinant $S$. aureus CodY-His 6 protein and FAM-labeled fragments in binding buffer $(20 \mathrm{mM}$ Tris- $\mathrm{Cl}$ [pH 8.0], 50 $\mathrm{mM} \mathrm{KCl}, 2 \mathrm{mM} \mathrm{MgCl} 2,5 \%$ [v/v] glycerol, 0.05\% [v/v] Nonidet P-40, $1 \mathrm{mM}$ dithiothritol [DTT], $0.025 \mathrm{mg} \mathrm{ml}^{-1}$ salmon sperm DNA). Samples $(20 \mu \mathrm{l})$ containing various amounts of CodY$\mathrm{His}_{6}, 200 \mathrm{fmol}$ of 6-FAM-labled DNA fragment, $2 \mathrm{mM} \mathrm{GTP}$, and $10 \mathrm{mM}$ (each) ILV were incubated for $20 \mathrm{~min}$ at $25^{\circ} \mathrm{C}$ in a thermomixer (Eppendorf) with agitation ( $250 \mathrm{rpm}$ ). The samples were separated on $8 \%$ non-denaturing 35 mM HEPES ( $\mathrm{pH} 7.4$ )-43 mM imidazole$10 \mathrm{mM}$ ILV polyacrylamide gels for $40 \mathrm{~min}$ at $200 \mathrm{~V}$. Fluorescent DNA fragments were detected using a computer-controlled ImageQuant LAS 4000 biomolecular imager (GE Healthcare Life Sciences) using a SYBR filter set. Quantitative analysis of CodY binding to the $r s a D$ promoter and polC was performed using ImageJ software (Schneider et al., 2012) as previously described (Kaiser et al., 2017). Since the binding curve of the $r s a D$ promoter appeared to have a sigmoidal shape, the data from three independent experiments were fitted to the Hill equation $\Theta=\mathrm{C}^{\mathrm{h}} /\left(\mathrm{C}^{\mathrm{h}}+K_{0.5^{h}}\right)$ using Prism (ver. 8; GraphPad Software). In this equation, $\Theta$ is the fraction of bound DNA, $C$ is the concentration of CodY, $K_{0.5}$ is the binding constant, and $\mathrm{h}$ is the Hill coefficient. $K_{0.5}$ and $\mathrm{h}$ shown are from fitted data where $r^{2}>0.8$.

\section{ChIP assays.}

The chromatin immunoprecipitation assays were performed as previously described (Sengupta et al., 2012), with modifications as previously described (Batte et al., 2018). Foldchange was calculated by using the following equation:(rsaD IP copy \# / gyrA IP copy \#) / ( $r s a D$ input copy \# / gyrA input copy number).

\section{Northern blots.}

Northern blots were perform as previously described (Germain-Amiot et al., 2019). Briefly, $10 \mu \mathrm{g}$ of total RNAs were loaded and separated in $8 \%$ polyacrylamide/8M urea gels. The 
RNAs were probed with ${ }^{32} \mathrm{P} 5$ '-end labeled oligonucleotides (Supplementary Table S2B) and detected using a Typhoon FLA 9500 scanner (GE Healthcare). Total RNAs extracted at different time intervals. RNA amounts were quantified using a Typhoon FLA 9500 scanner (GE Healthcare) and tmRNA as an internal loading control.

\section{RNA:RNA EMSAs and toeprints.}

RNAs were transcribed in vitro from PCR products using primers listed in Table S4 and the MEGAscript T7 kit (Thermo Fisher) according to the manufacturer's recommendations. RNAs were gel-purified, eluted, and precipitated with ethanol in the presence of $0.3 \mathrm{M}$ sodium acetate. EMSAs and toeprinting assays were done as previously described (Germain-Amiot et al., 2019) with some modifications. Native gel shift assays were conducted with 5 fmoles of purified labelled alsS. To assess binding specificity, 250 fmoles of unlabeled als $S$ or SprA2 were individually added to the complex. The results were analysed on a Phosphorlmager and Kd values determined accordingly.

\section{Aerobic growth assays.}

Cells were grown in $250 \mathrm{ml}$ DeLong shake flasks filled with $25 \mathrm{ml}$ of TSB containing either $14 \mathrm{mM}$ glucose or $35 \mathrm{mM}$ glucose (10:1 flask-to-medium ratio). Cells were sampled and plated each day and incubated overnight onto tryptic soy broth agar plates without any additional glucose for colony forming units (CFU) counts. CFUs were counted within two days of plating. Percent survival was calculated by setting CFUs after one day to $100 \%$ and then normalizing CFUs of each proceeding day to day one CFUs.

\section{Metabolite assays.}

Aerobic growth of strains was performed as described above. On the indicated day, culture supernatant samples were centrifuged, filtered using Spin-X 0.22 um column filters (Corning), and stored at $-20^{\circ} \mathrm{C}$ until use. Acetate and glucose from culture supernatants were measured using commercially available kits (R-Biopharm, Marshall, MI). Acetoin was measured as previously described (Nicholson, 2008). Briefly, $200 \mu \mathrm{L}$ of diluted culture 
supernatants, $140 \mu \mathrm{L}$ of $0.5 \%$ [w/v] creatine, $200 \mu \mathrm{L} 5 \%$ [w/v] 1-naphthol, and $200 \mu \mathrm{L} 40 \%$ $[\mathrm{w} / \mathrm{v}] \mathrm{KOH}$ were combined in a semi-micro cuvette. Absorbance at $560 \mathrm{~nm}$ was measured after $15 \mathrm{~min}$ and acetoin concentration was calculated using a molar extinction coefficient $(\varepsilon$ $\left.=2.941 \mathrm{~L} \mathrm{~mol}^{-1} \mathrm{~cm}^{-1}\right)$. Solutions were made fresh to prevent substrate degradation.

\section{AlsSD activity assays.}

At mid-exponential phase $\left(\mathrm{OD}_{600}=0.4-0.6\right)$ cells were pelleted, washed with $\mathrm{PBS}$, and frozen at $-80^{\circ} \mathrm{C}$ until use. Cell lysates were prepared as previously described (Kaiser et al., 2018, Mlynek et al., 2018). Briefly, pellets were resuspended in Buffer A (20 mM Tris-HCl [pH 7.9], $500 \mathrm{mM} \mathrm{NaCl}, 5 \%$ [v/v] glycerol, $5 \mathrm{mM}$ imidazole) supplemented with $1 \mathrm{mM}$ phenylmethanesulfonyl fluoride (PMSF). $10 \mu \mathrm{L}$ of lysostaphin $\left(2 \mathrm{mg} \mathrm{mL}^{-1}\right)$ was added to tubes and incubated at $37^{\circ} \mathrm{C}$ for 30 min to generate protoplasts. Then, cells were sonicated for 3 min at $60 \%$ amplitude with $10 \mathrm{sec}$ pulses and $5 \mathrm{sec}$ between pulses using a Branson Sonifier equipped with a water-jacketed cup horn chilled to $5^{\circ} \mathrm{C}$. Samples were centrifuged at $18800 \times \mathrm{g}$ for $2 \mathrm{~min}$ at $4^{\circ} \mathrm{C}$ to remove cell debris. Supernatants were transferred to a clean tube and protein levels were quantified using a Pierce Coomassie protein assay kit according to the manufacturer's instructions. Acetolactate synthase-decarboxylase activity assays were performed as previously described (Monnet, 1994). Briefly, reaction mixtures containing $70 \mathrm{mM}$ sodium acetate buffer $\mathrm{pH} 5.3,0.17 \mathrm{mM}$ thiamine pyrophosphate, and cell lysate pre-incubated at $37 \mathrm{deg}$ for $5 \mathrm{~min}$. Reactions were initiated by adding $50 \mathrm{mM}$ pyruvate incubated at $37^{\circ} \mathrm{C}$ for $30 \mathrm{~min}$. Acetoin formation was measured using the Westerfield method (Westerfield, 1945). Briefly, a 200- $\mu \mathrm{L}$ sample of reacted assay mixtures was combined with $800 \mu \mathrm{L} 0.45 \mathrm{~N} \mathrm{NaOH} .1 \mathrm{~mL} 0.5 \%$ [w/v] creatine and $1 \mathrm{~mL}$ of $5 \%[\mathrm{w} / \mathrm{v}] 1$ naphthol were subsequently added, then reaction mixtures were incubated for $15 \mathrm{~min}$. Absorbance at $560 \mathrm{~nm}$ was read and acetoin concentration was calculated using the molar extinction coefficient.

Flow cytometry analysis. 
A 1-ml sample of cells carrying the indicated gfp reporter was pelleted during exponential growth $\left(\mathrm{OD}_{600}\right.$ 0.4-0.6), washed with PBS, and fixed with $200 \mu \mathrm{l}$ of $3 \%[\mathrm{w} / \mathrm{v}]$ paraformaldehyde (PFA, in PBS) for 45 min. PFA was then washed away and fixed cells were resuspended in $500 \mu \mathrm{l}$ PBS. Cells were stained with SYTO 40 Blue for $20 \mathrm{~min}$. Stained cells were analyzed using a computer-controlled FACStar Plus dual-laser system (Becton, Dickinson) and FCS Express software (version 4.0; DeNovo Software). Populations were selected by gating forward scatter in conjunction with SYTO 40 Blue stain. The limit of detection was determined using cells lacking a gfp reporter construct and defined as the signal intensity encompassing $99 \%$ of this population. Cells that were $\mathrm{GFP}^{+}$were identified as any cell exceeding the limit of detection and enumerated for each genotype.

\section{Statistical Analyses}

Prism version 8 (GraphPad) was used for all statistical analyses as indicated.

\section{Acknowledgements}

We thank Deepak Sharma, Nicholas Waters, and Manus Patten for technical assistance, and Paul Fey and Svetlana Chabelskaya for generously providing S. epidermidis strains and plasmids, respectively. This work was supported in part by a Pathway to Independence Award from the National Institute of General Medical Sciences (GM099893) and Georgetown University Startup funds to SRB, and by l'Agence Nationale pour la Recherche (ANR-15-CE12-0003-01, "sRNA-Fit") to BF. ANK was supported by an Achievement Rewards for College Students (ARCS) Danaher Scholar award from the Metropolitan Washington Chapter of the ARCS Foundation. MS was supported by the region Bretagne grant SAD SARS_2 \#9181 (to YA). YA was supported by a Marie Curie International Incoming Fellowship (project 621959—SarHyb) within the 7th European Community Framework Programme. The authors thank the Roscoff Bioinformatics platform ABiMS (http://abims.sb-roscoff.fr) for providing computational resources. The funders had no role in study design, data collection and interpretation, or the decision to submit the work for publication. 


\section{Author Contributions}

Conception or design of the study: ANK, YA, BF, SRB. qRT-PCR, $\Delta r s a D$ mutant construction and complementation, cell death assays, physiological measurements, translational fusions, CodY gel shifts: ANK and JF. Northern blots, RNA-RNA gel shifts, toeprint analysis: NGA and YA. ChIP-PCR: GS. RNA-seq and in silico predictions: YA and MS. Analysis and interpretation of the data: ANK, GS, ME, YA, BF, SRB. Writing original draft: ANK, SRB. Reviewing and editing of draft: ANK, YA, GS, BF, SRB. 


\section{References}

Abu-Qatouseh, L.F., Chinni, S.V., Seggewiss, J., Proctor, R.A., Brosius, J., Rozhdestvensky, T.S., Peters, G., von Eiff, C., and Becker, K. (2010) Identification of differentially expressed small non-protein-coding RNAs in Staphylococcus aureus displaying both the normal and the small-colony variant phenotype. J Mol Med (Berl). 88: 565-575.

Anders, S., and Huber, W. (2010) Differential expression analysis for sequence count data. Genome Biol. 11: R106.

Baba, T., Bae, T., Schneewind, O., Takeuchi, F., and Hiramatsu, K. (2008) Genome sequence of Staphylococcus aureus strain Newman and comparative analysis of staphylococcal genomes: polymorphism and evolution of two major pathogenicity islands. J Bacteriol 190: 300-310.

Balaban, N., and Novick, R.P. (1995) Autocrine regulation of toxin synthesis by Staphylococcus aureus. Proc Natl Acad Sci U S A. 92: 1619-1623.

Batte, J.L., Sahukhal, G.S., and Elasri, M.O. (2018) MsaB and CodY Interact To Regulate Staphylococcus aureus Capsule in a Nutrient-Dependent Manner. J Bacteriol 200.

Beaume, M., Hernandez, D., Farinelli, L., Deluen, C., Linder, P., Gaspin, C., Romby, P., Schrenzel, J., and Francois, P. (2010) Cartography of methicillin-resistant S. aureus transcripts: detection, orientation and temporal expression during growth phase and stress conditions. PLoS One 5: e10725.

Beisel, C.L., and Storz, G. (2010) Base pairing small RNAs and their roles in global regulatory networks. FEMS Microbiol Rev 34: 866-882.

Bennett, H.J., Pearce, D.M., Glenn, S., Taylor, C.M., Kuhn, M., Sonenshein, A.L., Andrew, P.W., and Roberts, I.S. (2007) Characterization of relA and codY mutants of Listeria monocytogenes: identification of the CodY regulon and its role in virulence. $\mathrm{Mol}$ Microbiol 63: 1453-1467.

Bohn, C., Rigoulay, C., Chabelskaya, S., Sharma, C.M., Marchais, A., Skorski, P., BorezeeDurant, E., Barbet, R., Jacquet, E., Jacq, A., Gautheret, D., Felden, B., Vogel, J., and Bouloc, P. (2010a) Experimental discovery of small RNAs in Staphylococcus aureus reveals a riboregulator of central metabolism. Nucleic Acids Res 38: 6620-6636. 
Bohn, C., Rigoulay, C., Chabelskaya, S., Sharma, C.M., Marchais, A., Skorski, P., BorezéeDurant, E., Barbet, R., Jacquet, E., Jacq, A., Gautheret, D., Felden, B., Vogel, J., and Bouloc, P. (2010b) Experimental discovery of small RNAs in Staphylococcus aureus reveals a riboregulator of central metabolism. Nucleic Acids Res. 38: 6620-6636.

Boisset, S., Geissmann, T., Huntzinger, E., Fechter, P., Bendridi, N., Possedko, M., Chevalier, C., Helfer, A.C., Benito, Y., Jacquier, A., Gaspin, C., Vandenesch, F., and Romby, P. (2007) Staphylococcus aureus RNAIll coordinately represses the synthesis of virulence factors and the transcription regulator Rot by an antisense mechanism. Genes Dev. 21: 1353-1366.

Bolger, A.M., Lohse, M., and Usadel, B. (2014) Trimmomatic: a flexible trimmer for Illumina sequence data. Bioinformatics 30: 2114-2120.

Bose, J.L. (2014) Genetic manipulation of staphylococci. Methods Mol Biol 1106: 101-111.

Bose, J.L., Fey, P.D., and Bayles, K.W. (2013) Genetic tools to enhance the study of gene function and regulation in Staphylococcus aureus. Appl Environ Microbiol 79: 22182224.

Brinsmade, S.R. (2016) CodY, a master integrator of metabolism and virulence in Grampositive bacteria. Curr Genet. 63: 417-425.

Broach, W.H., Weiss, A., and Shaw, L.N. (2016) Transcriptomic analysis of staphylococcal sRNAs: insights into species-specific adaption and the evolution of pathogenesis. Microb Genom 2: e000065.

Bronesky, D., Desgranges, E., Corvaglia, A., Francois, P., Caballero, C.J., Prado, L., Toledo-Arana, A., Lasa, I., Moreau, K., Vandenesch, F., Marzi, S., Romby, P., and Caldelari, I. (2019) A multifaceted small RNA modulates gene expression upon glucose limitation in Staphylococcus aureus. EMBO J 38.

Bronsard, J., Pascreau, G., Sassi, M., Mauro, T., Augagneur, Y., and Felden, B. (2017) sRNA and cis-antisense sRNA identification in Staphylococcus aureus highlights an unusual sRNA gene cluster with one encoding a secreted peptide. Sci Rep 7: 4565. 
Busch, A., Richter, A.S., and Backofen, R. (2008) IntaRNA: efficient prediction of bacterial sRNA targets incorporating target site accessibility and seed regions. Bioinformatics 24: 2849-2856.

Carroll, R.K., Weiss, A., Broach, W.H., Wiemels, R.E., Mogen, A.B., Rice, K.C., and Shaw, L.N. (2016) Genome-wide Annotation, Identification, and Global Transcriptomic Analysis of Regulatory or Small RNA Gene Expression in Staphylococcus aureus. MBio. 7: e01990-01915.

Château, A., van Schaik, W., Six, A., Aucher, W., and Fouet, A. (2011) CodY regulation is required for full virulence and heme iron acquisition in Bacillus anthracis. FASEB J. 25: 4445-4456.

Chaturongakul, S., Raengpradub, S., Wiedmann, M., and Boor, K.J. (2008) Modulation of stress and virulence in Listeria monocytogenes. Trends Microbiol 16: 388-396.

Chaudhari, S.S., Thomas, V.C., Sadykov, M.R., Bose, J.L., Ahn, D.J., Zimmerman, M.C., and Bayles, K.W. (2016) The LysR-type transcriptional regulator, CidR, regulates stationary phase cell death in Staphylococcus aureus. Mol Microbiol. 101: 942-953.

Cheung, A.L., Bayer, A.S., Zhang, G., Gresham, H., and Xiong, Y.Q. (2004) Regulation of virulence determinants in vitro and in vivo in Staphylococcus aureus. FEMS Immunol Med Microbiol 40: 1-9.

Cheung, G., Wang, R., Khan, B., Sturdevant, D., and Otto, M. (2011) Role of the accessory gene regulator agr in community-associated methicillin-resistant Staphylococcus aureus pathogenesis. Infect Immun. 79: 1927-1935.

den Hengst, C.D., van Hijum, S.A.F.T., Geurts, J.M.W., Nauta, A., Kok, J., and Kuipers, O.P. (2005) The Lactococcus lactis CodY regulon: identification of a conserved cisregulatory element. J Biol Chem. 280: 34332-34342.

Desai, R., Pannaraj, P.S., Agopian, J., Sugar, C.A., Liu, G.Y., and Miller, L.G. (2011) Survival and transmission of community-associated methicillin-resistant Staphylococcus aureus from fomites. Am J Infect Control. 39: 219-225.

Diep, B.A., Gill, S.R., Chang, R.F., Phan, T.H., Chen, J.H., Davidson, M.G., Lin, F., Lin, J., Carleton, H.A., Mongodin, E.F., Sensabaugh, G.F., and Perdreau-Remington, F. 
(2006) Complete genome sequence of USA300, an epidemic clone of communityacquired meticillin-resistant Staphylococcus aureus. Lancet. 367: 731-739.

Dineen, S.S., McBride, S.M., and Sonenshein, A.L. (2010) Integration of metabolism and virulence by Clostridium difficile CodY. J Bacteriol. 192: 5350-5362.

Eggenhofer, F., Tafer, H., Stadler, P., and Hofacker, I. (2011) RNApredator: fast accessibility-based prediction of sRNA targets. Nucleic Acids Res. 39: W149-154.

Escolar, L., Perez-Martin, J., and de Lorenzo, V. (1999) Opening the iron box: transcriptional metalloregulation by the Fur protein. $J$ Bacteriol 181: 6223-6229.

Eyraud, A., Tattevin, P., Chabelskaya, S., and Felden, B. (2014) A small RNA controls a protein regulator involved in antibiotic resistance in Staphylococcus aureus. Nucleic Acids Res. 42: 4892-4905.

Geissmann, T., Chevalier, C., Cros, M., Boisset, S., Fechter, P., Noirot, C., Schrenzel, J., François, P., Vandenesch, F., Gaspin, C., and Romby, P. (2009) A search for small noncoding RNAs in Staphylococcus aureus reveals a conserved sequence motif for regulation. Nucleic Acids Res. 37: 7239-7257.

Germain-Amiot, N., Augagneur, Y., Camberlein, E., Nicolas, I., Lecureur, V., Rouillon, A., and Felden, B. (2019) A novel Staphylococcus aureus cis-trans type I toxin-antitoxin module with dual effects on bacteria and host cells. Nucleic Acids Res 47: 1759-1773.

Graham, P.L., Lin, S.X., and Larson, E.L. (2006) A U.S. population-based survey of Staphylococcus aureus colonization. Ann Intern Med. 144: 318-325.

Guillet, J., Hallier, M., and Felden, B. (2013) Emerging functions for the Staphylococcus aureus RNome. PLoS Pathog. 9: e1003767.

Hecker, M., Pané-Farré, J., and Völker, U. (2007) SigB-dependent general stress response in Bacillus subtilis and related gram-positive bacteria. Annu Rev Microbiol. 61: 215236.

Hendriksen, W.T., Bootsma, H.J., Estevão, S., Hoogenboezem, T., de Jong, A., de Groot, R., Kuipers, O.P., and Hermans, P.W. (2008) CodY of Streptococcus pneumoniae: link between nutritional gene regulation and colonization. J Bacteriol. 190: 590-601. 
Howden, B.P., Beaume, M., Harrison, P.F., Hernandez, D., Schrenzel, J., Seemann, T., Francois, P., and Stinear, T.P. (2013) Analysis of the small RNA transcriptional response in multidrug-resistant Staphylococcus aureus after antimicrobial exposure. Antimicrob Agents Chemother 57: 3864-3874.

Ibberson, C., Jones, C., Singh, S., Wise, M., Hart, M., Zurawski, D., and Horswill, A. (2014) Staphylococcus aureus hyaluronidase is a CodY-regulated virulence factor. Infect. Immun. 82: 4253-4264.

Ivain, L., Bordeau, V., Eyraud, A., Hallier, M., Dreano, S., Tattevin, P., Felden, B., and Chabelskaya, S. (2017) An in vivo reporter assay for sRNA-directed gene control in Gram-positive bacteria: identifying a novel sRNA target in Staphylococcus aureus. Nucleic Acids Res 45: 4994-5007.

Kaiser, J.C., King, A.N., Grigg, J.C., Sheldon, J.R., D.R., E., Murphy, M.E., Brinsmade, S.R., and Heinrichs, D.E. (2017) Repression of branched-chain amino acid synthesis in Staphylococcus aureus is mediated by isoleucine via CodY, and by a leucine-rich attenuator peptide. PLoS Genet. In Press.

Kaiser, J.C., King, A.N., Grigg, J.C., Sheldon, J.R., Edgell, D.R., Murphy, M.E.P., Brinsmade, S.R., and Heinrichs, D.E. (2018) Repression of branched-chain amino acid synthesis in Staphylococcus aureus is mediated by isoleucine via CodY, and by a leucine-rich attenuator peptide. PLoS Genet 14: e1007159.

Kavanaugh, J.S., and Horswill, A.R. (2016) Impact of Environmental Cues on Staphylococcal Quorum Sensing and Biofilm Development. J Biol Chem. 291: 1255612564.

Kery, M.B., Feldman, M., Livny, J., and Tjaden, B. (2014) TargetRNA2: identifying targets of small regulatory RNAs in bacteria. Nucleic Acids Res 42: W124-129.

King, A.N., Borkar, S.A., Samuels, D.J., Batz, Z., Bulock, L.L., Sadykov, M.R., Bayles, K.W., and Brinsmade, S.R. (2018) Guanine limitation results in CodY-dependent and independent alteration of Staphylococcus aureus physiology and gene expression. $J$ Bacteriol. 200: e00136-00118. 
Lemos, J.A., Nascimento, M.M., Lin, V.K., Abranches, J., and Burne, R.A. (2008) Global regulation by (p)ppGpp and CodY in Streptococcus mutans. J Bacteriol. 190: 52915299.

Lennox, E.S. (1955) Transduction of linked genetic characters of the host by bacteriophage P1. Virology 1: 190-206.

Lobel, L., Sigal, N., Borovok, I., Ruppin, E., and Herskovits, A.A. (2012) Integrative genomic analysis identifies isoleucine and CodY as regulators of Listeria monocytogenes virulence. PLoS Genet. 8: e1002887.

Luong, T.T., and Lee, C.Y. (2007) Improved single-copy integration vectors for Staphylococcus aureus. J Microbiol Methods 70: 186-190.

Majerczyk, C.D., Dunman, P.M., Luong, T.T., Lee, C.Y., Sadykov, M.R., Somerville, G.A., Bodi, K., and Sonenshein, A.L. (2010) Direct targets of CodY in Staphylococcus aureus. J Bacteriol. 192: 2861-2877.

Malke, H., Steiner, K., McShan, W.M., and Ferretti, J.J. (2006) Linking the nutritional status of Streptococcus pyogenes to alteration of transcriptional gene expression: the action of CodY and RelA. Int J Med Microbiol. 296: 259-275.

Mann, M., Wright, P.R., and Backofen, R. (2017) IntaRNA 2.0: enhanced and customizable prediction of RNA-RNA interactions. Nucleic Acids Res 45: W435-W439.

Manna, A.C., Kim, S., Cengher, L., Corvaglia, A., Leo, S., Francois, P., and Cheung, A.L. (2018) Small RNA teg49 Is Derived from a sarA Transcript and Regulates Virulence Genes Independent of SarA in Staphylococcus aureus. Infect Immun 86.

Marroquin, S., Gimza, B., Tomlinson, B., Stein, M., Frey, A., Keogh, R.A., Zapf, R., Todd, D.A., Cech, N.B., Carroll, R.K., and Shaw, L.N. (2019) MroQ Is a Novel Abi-Domain Protein That Influences Virulence Gene Expression in Staphylococcus aureus via Modulation of Agr Activity. Infect Immun 87.

Mars, R.A., Nicolas, P., Denham, E.L., and van Dijl, J.M. (2016) Regulatory RNAs in Bacillus subtilis: a Gram-Positive Perspective on Bacterial RNA-Mediated Regulation of Gene Expression. Microbiol Mol Biol Rev 80: 1029-1057. 
Mashruwala, A.A., and Boyd, J.M. (2017) The Staphylococcus aureus SrrAB Regulatory System Modulates Hydrogen Peroxide Resistance Factors, Which Imparts Protection to Aconitase during Aerobic Growth. PLoS One 12: e0170283.

Mashruwala, A.A., Guchte, A.V., and Boyd, J.M. (2017) Impaired respiration elicits SrrABdependent programmed cell lysis and biofilm formation in Staphylococcus aureus. Elife 6.

Masse, E., and Gottesman, S. (2002) A small RNA regulates the expression of genes involved in iron metabolism in Escherichia coli. Proc Natl Acad Sci U S A 99: 46204625.

Mertz, P.M., Cardenas, T.C., Snyder, R.V., Kinney, M.A., Davis, S.C., and Plano, L.R. (2007) Staphylococcus aureus virulence factors associated with infected skin lesions: influence on the local immune response. Arch Dermatol. 143: 1259-1263.

Mitchell, G., Fugere, A., Pepin Gaudreau, K., Brouillette, E., Frost, E.H., Cantin, A.M., and Malouin, F. (2013) SigB is a dominant regulator of virulence in Staphylococcus aureus small-colony variants. PLoS One 8: e65018.

Miyakoshi, M., Chao, Y., and Vogel, J. (2015) Cross talk between ABC transporter mRNAs via a target mRNA-derived sponge of the GcvB small RNA. EMBO J 34: 1478-1492.

Mlynek, K.D., Sause, W.E., Moormeier, D.E., Sadykov, M.R., Hill, K.R., Torres, V.J., Bayles, K.W., and Brinsmade, S.R. (2018) Nutritional regulation of the Sae two-component system by CodY in Staphylococcus aureus. J Bacteriol. 200: e00012-00018.

Monnet, C., Phalip, V., Schmitt, P., Divies, C. (1994) Comparison of a-acetolactate synthase and $\alpha$-acetolactate decarboxylase in Lactococcus spp. and Leuconostoc spp. Biotech. Lett. 16: 257-262.

Moormeier, D., Endres, J., Mann, E., Sadykov, M., Horswill, A., Rice, K., Fey, P., and Bayles, K. (2013) Use of microfluidic technology to analyze gene expression during Staphylococcus aureus biofilm formation reveals distinct physiological niches. Appl Environ Microbiol. 79: 3413-3424.

Nicholson, W.L. (2008) The Bacillus subtilis ydjL (bdhA) gene encodes acetoin reductase/2,3-butanediol dehydrogenase. Appl Environ Microbiol. 74: 6832-6838. 
Nielsen, J.S., Christiansen, M.H., Bonde, M., Gottschalk, S., Frees, D., Thomsen, L.E., and Kallipolitis, B.H. (2011) Searching for small sigmaB-regulated genes in Staphylococcus aureus. Arch Microbiol 193: 23-34.

Novick, R. (2003) Autoinduction and signal transduction in the regulation of staphylococcal virulence. Mol Microbiol. 48: 1429-1449.

Novick, R.P. (1991) Genetic systems in staphylococci. Methods Enzymol. 204.

Novick, R.P., Ross, H.F., Projan, S.J., Kornblum, J., Kreiswirth, B., and Moghazeh, S. (1993) Synthesis of staphylococcal virulence factors is controlled by a regulatory RNA molecule. EMBO J. 12: 3967-3975.

Olson, M.E., Nygaard, T.K., Ackermann, L., Watkins, R.L., Zurek, O.W., Pallister, K.B., Griffith, S., Kiedrowski, M.R., Flack, C.E., Kavanaugh, J.S., Kreiswirth, B.N., Horswill, A.R., and Voyich, J.M. (2013) Staphylococcus aureus nuclease is an SaeRSdependent virulence factor. Infect Immun. 81: 1316-1324.

Pané-Farré, J., Jonas, B., Hardwick, S.W., Gronau, K., Lewis, R.J., Hecker, M., and Engelmann, S. (2009) Role of RsbU in controlling SigB activity in Staphylococcus aureus following alkaline stress. J Bacteriol. 191: 2561-2573.

Parlet, C.P., Brown, M.M., and Horswill, A.R. (2019) Commensal Staphylococci Influence Staphylococcus aureus Skin Colonization and Disease. Trends Microbiol 27: 497507.

Pohl, K., Francois, P., Stenz, L., Schlink, F., Geiger, T., Herbert, S., Goerke, C., Schrenzel, J., and Wolz, C. (2009) CodY in Staphylococcus aureus: a regulatory link between metabolism and virulence gene expression. J Bacteriol. 191: 2953-2963.

Queck, S.Y., Jameson-Lee, M., Villaruz, A.E., Bach, T.H., Khan, B.A., Sturdevant, D.E., Ricklefs, S.M., Li, M., and Otto, M. (2008) RNAlll-independent target gene control by the agr quorum-sensing system: insight into the evolution of virulence regulation in Staphylococcus aureus. Mol Cell. 32: 150-158.

Quereda, J.J., and Cossart, P. (2017) Regulating Bacterial Virulence with RNA. Annu Rev Microbiol 71: 263-280. 
Raden, M., Ali, S.M., Alkhnbashi, O.S., Busch, A., Costa, F., Davis, J.A., Eggenhofer, F., Gelhausen, R., Georg, J., Heyne, S., Hiller, M., Kundu, K., Kleinkauf, R., Lott, S.C., Mohamed, M.M., Mattheis, A., Miladi, M., Richter, A.S., Will, S., Wolff, J., Wright, P.R., and Backofen, R. (2018) Freiburg RNA tools: a central online resource for RNAfocused research and teaching. Nucleic Acids Res 46: W25-W29.

Recsei, P., Kreiswirth, B., O'Reilly, M., Schlievert, P., Gruss, A., and Novick, R. (1986) Regulation of exoprotein gene expression in Staphylococcus aureus by agr. Mol Gen Genet. 202: 58-61.

Rice, K.C., Mann, E.E., Endres, J.L., Weiss, E.C., Cassat, J.E., Smeltzer, M.S., and Bayles, K.W. (2007) The cidA murein hydrolase regulator contributes to DNA release and biofilm development in Staphylococcus aureus. Proc Natl Acad Sci U S A. 104: 81138118.

Richards, G.R., and Vanderpool, C.K. (2011) Molecular call and response: the physiology of bacterial small RNAs. Biochim Biophys Acta 1809: 525-531.

Rogers, K.L., Fey, P.D., and Rupp, M.E. (2009) Coagulase-negative staphylococcal infections. Infect Dis Clin North Am. 23: 73-98.

Romilly, C., Lays, C., Tomasini, A., Caldelari, I., Benito, Y., Hammann, P., Geissmann, T., Boisset, S., Romby, P., and Vandenesch, F. (2014) A non-coding RNA promotes bacterial persistence and decreases virulence by regulating a regulator in Staphylococcus aureus. PLoS Pathog. 10: e1003979.

Russell, J.B. (1991) Resistance of Streptococcus bovis to acetic acid at low pH: relationship between intracellular pH and anion accumulation. Appl Environ Microbiol 57: 255-259.

Sassi, M., Augagneur, Y., Mauro, T., Ivain, L., Chabelskaya, S., Hallier, M., Sallou, O., and Felden, B. (2015a) SRD: a Staphylococcus regulatory RNA database. RNA 21: 10051017.

Sassi, M., Sharma, D., Brinsmade, S., Felden, B., and Augagneur, Y. (2015b) Genome Sequence of the Clinical Isolate Staphylococcus aureus subsp. aureus Strain UAMS1. Genome Announc. 3: e01584-01514. 
Schenk, S., and Laddaga, R.A. (1992) Improved method for electroporation of Staphylococcus aureus. FEMS Microbiol. Lett. 73: 133-138.

Schneider, C.A., Rasband, W.S., and Eliceiri, K.W. (2012) NIH Image to ImageJ: 25 years of image analysis. Nat Methods 9: 671-675.

Sengupta, M., Jain, V., Wilkinson, B.J., and Jayaswal, R.K. (2012) Chromatin immunoprecipitation identifies genes under direct VraSR regulation in Staphylococcus aureus. Can J Microbiol 58: 703-708.

Shimoni, Y., Friedlander, G., Hetzroni, G., Niv, G., Altuvia, S., Biham, O., and Margalit, H. (2007) Regulation of gene expression by small non-coding RNAs: a quantitative view. Mol Syst Biol 3: 138.

Sonenshein, A.L. (2005) CodY, a global regulator of stationary phase and virulence in Grampositive bacteria. Curr Opin Microbiol 8: 203-207.

Storz, G., Vogel, J., and Wassarman, K.M. (2011) Regulation by small RNAs in bacteria: expanding frontiers. Mol Cell 43: 880-891.

Thomas, V.C., Sadykov, M.R., Chaudhari, S.S., Jones, J., Endres, J.L., Widhelm, T.J., Ahn, J.S., Jawa, R.S., Zimmerman, M.C., and Bayles, K. (2014) A central role for carbonoverflow pathways in the modulation of bacterial cell death. PLoS Pathog. 10: e1004205.

Tuchscherr, L., Bischoff, M., Lattar, S.M., Noto Llana, M., Pfortner, H., Niemann, S., Geraci, J., Van de Vyver, H., Fraunholz, M.J., Cheung, A.L., Herrmann, M., Volker, U., Sordelli, D.O., Peters, G., and Loffler, B. (2015) Sigma Factor SigB Is Crucial to Mediate Staphylococcus aureus Adaptation during Chronic Infections. PLoS Pathog 11: e1004870.

Vallejo, A.N., Pogulis, R.J., and Pease, L.R. (2008) PCR mutagenesis by overlap extension and gene SOE. CSH Protoc. 2008:pdb.prot4861.

Waters, N.R., Samuels, D.J., Behera, R.K., Livny, J., Rhee, K.Y., Sadykov, M.R., and Brinsmade, S.R. (2016) A spectrum of CodY activities drives metabolic reorganization and virulence gene expression in Staphylococcus aureus. Mol Microbiol. 101: 495514. 
Westerfield, W.W. (1945) A colorimetric determination of blood acetoin. J Biol Chem 161: 495-502.

Wright, P.R., Georg, J., Mann, M., Sorescu, D.A., Richter, A.S., Lott, S., Kleinkauf, R., Hess, W.R., and Backofen, R. (2014) CopraRNA and IntaRNA: predicting small RNA targets, networks and interaction domains. Nucleic Acids Res 42: W119-123.

Zapf, R.L., Wiemels, R.E., Keogh, R.A., Holzschu, D.L., Howell, K.M., Trzeciak, E., Caillet, A.R., King, K.A., Selhorst, S.A., Naldrett, M.J., Bose, J.L., and Carroll, R.K. (2019) The Small RNA Teg41 Regulates Expression of the Alpha Phenol-Soluble Modulins and Is Required for Virulence in Staphylococcus aureus. MBio 10.

Zhang, X., Bayles, K.W., and Luca, S. (2017) Staphylococcus aureus CidC Is a Pyruvate:Menaquinone Oxidoreductase. Biochemistry 56: 4819-4829. 


\section{Figure Legends}

Figure 1. sRNAs repressed by CodY in three clinical isolates of Staphylococcus aureus: Newman, USA300, and UAMS-1. Venn diagram displaying SRNAs more than 2fold up-regulated in the $\Delta c o d Y$ mutant compared to WT; blue indicates strain Newman, red indicates strain USA300, and green indicates strain UAMS-1. Full data are available in Table $\mathrm{S} 1$ in the supplemental material.

Figure 2. RsaD is regulated by CodY in multiple staphylococcal species. A. RsaD is located in the intergenic region between nucleoside permease (SAR0655; nupC2) and a hypothetical protein belonging to the YitT protein family (SAR0656) in S. aureus and 14 other species. B. CodY motifs were identified by BLAST in the $r s a D$ promoter region in multiple staphylococci; an alignment of these sequences was performed used MEGA7 (color corresponds to nucleotides: green $=A$, red $=T$, blue $=C$, purple $=G$ ). Asterisks indicate nucleotides conserved within the CodY motif. The transcriptional start of $r s a D(+1)$ is annotated. C. RsaD transcript abundance for the indicated strains during mid-exponential growth in TSB at $37^{\circ} \mathrm{C}$. Copies of $r s a D$ transcript are normalized to copies of polC transcript (S. aureus) or gyrA transcript (S. epidermidis). Data plotted are the mean \pm SEM values from at least three independent experiments. Statistical significance was assessed using Welch's t-test (WT compared to the $\Delta \operatorname{cod} Y$ mutant in each species) $\left({ }^{*} p<0.05\right)$.

Figure 3. CodY directly regulates $r s a D$ expression. A. Sequence of the $r s a D$ regulatory region. The CodY motif is underlined and in boldface, and the annotated $r s a D$ transcription start is indicated by the bent arrow. B. Purified $\mathrm{SaCodY}^{-H i s_{6}}$ was incubated with 6-FAMlabeled DNA fragments containing either $\mathrm{P}_{\text {rsaDWT }}$ or the coding sequence of polC in the presence of ILV and GTP for EMSA analysis. Band densitometry analysis was performed using Image $\mathrm{J}$ as previously described (Kaiser et al., 2018). The binding constants $\left(K_{0.5}\right)$ and Hill coefficient $(h)$ were determined by fitting the data to the Hill equation as described in Experimental Procedures. C. The indicated strains were grown in TSB at $37^{\circ} \mathrm{C}$ to midexponential phase, at which point the cells were harvested and RNA was isolated for qRTPCR analysis. gfp transcript normalized to polC transcript is shown. Data represent mean \pm 
SEM of three independent biological replicates. Statistical significance was assessed by one-way ANOVA with Tukey's post-test $\left({ }^{* *} p<0.01\right)$. D. Chromatin immunoprecipitation (ChIP-PCR) using an anti-His antibody was performed to determine whether CodY binds the $r s a D$ promoter during exponential phase. Fold-change was calculated as described in Experimental Procedures.

Figure 4. RsaD post-transcriptionally regulates alsS. A-C. Native EMSAs of purified ${ }^{32} \mathrm{P}-$ labelled alsS (5 fmoles) with increasing amounts of unlabeled WT RsaD (A), RsaD ${ }_{127-139}$ (B), and RsaD ${ }_{151-156}$ (C). To assess binding specificity, 250 fmoles of unlabeled alsS or SprA2 were individually added to the complex. 5 fmoles of WT RsaD was also used as a control for the EMSAs with $\mathrm{RsaD}_{127-139}$ (last lane, + RsaD). The data illustrate one representative experiment from at least three independent replicates. D. Cells harboring plasmids with $\mathrm{P}_{\text {tufA }}$ driving expression of als $S$ fused translationally to gfp and vector only or $\mathrm{P}_{\text {tufA }}$ driving expression of WT RsaD, RsaD mutated at nucleotides 127-139, or RsaD mutated at nucleotides $151-165$ were grown to mid-exponential phase in TSB at $37^{\circ} \mathrm{C}$. Cells were pelleted, washed with PBS, and then fixed with PFA for flow cytometry analysis. Data represent mean \pm SEM in at least three independent biological replicates. Statistical significance was assessed by one-way ANOVA with Tukey's post-test $\left(^{* * *} p<0.001,{ }^{* * * *}\right.$ $\mathrm{p}<0.0001)$.

Figure 5. RsaD prevents alsS translation by occluding the ribosome binding site. Toeprinting assays of $0.25 \mathrm{pmol}$ als $S$ in the absence (-) or presence (+) of $0.5 \mathrm{pmol}$ of purified $E$. coli $70 S$ ribosomes. The $A, C, G$ and $U$ lanes represent the als $S$ sequencing lanes. RsaD, truncated $R{ }_{1-126}$, mutated $R D_{127-139}$ or mutated $R D_{151-165}$ were added as indicated on the top of the figure. The arrow represents the toeprint position when observed. The gel illustrates one representative experiment among three.

Figure 6. RsaD is an sRNA effector of CodY used to post-transcriptionally regulate alsS mRNA and is responsible for the apparent positive CodY regulation of alsS 
mRNA. A. Wire diagram depicting the relationship between CodY, RsaD, and alsS. B. The indicated strains were grown in TSB at $37^{\circ} \mathrm{C}$ to mid-exponential phase, at which point the cells were harvested and RNA was isolated for qRT-PCR analysis. alsS transcript normalized to polC transcript is shown; data represent mean \pm SEM in at least three independent biological replicates. Statistical significance was assessed by one-way ANOVA with Tukey's post-test ( $\left.{ }^{*} p<0.05\right)$. C. Cells were grown in TSB to mid-exponential phase, at which point the cells were pelleted and lysed for AlsS activity assays measuring the conversion of pyruvate to acetoin. Data represent mean \pm SEM in three independent biological replicates. Statistical significance was assessed by one-way ANOVA with Tukey's post-test $\left({ }^{* \star} p<0.01\right)$.

\section{Figure 7. Expression of $r s a D$ over time in TSB with either $14 \mathrm{mM}$ or $35 \mathrm{mM}$ glucose.}

Northern blots were used to monitor $r s a D$ expression in UAMS-1 during exponential or postexponential phase $(\mathbf{A})$ and stationary phase $(\mathbf{B})$, with tmRNA used as an internal loading control. Relative amounts of RsaD RNA are indicated above each band in (A); expression values were set to one after two hours of growth in each condition and tmRNA used as the internal control. The expression values are the mean of three independent experiments.

\section{Figure 8. In Staphylococcus aureus clinical isolate UAMS-1, $\Delta$ rsaD mutant cells} exhibit a delayed cell death phenotype. A-D. Cells were grown in TSB containing $14 \mathrm{mM}$ glucose or TSB containing $35 \mathrm{mM}$ glucose for 5 days, as indicated. CFUs were serially diluted and plated each day and counted. Percent survival was calculated by setting day 1 CFUs to $100 \%$ and normalizing each proceeding day to CFUs collected on day 1 . Supernatants were collected and filtered to remove cells for $\mathrm{pH}$ measurements. Data represent mean \pm SEM in three independent biological replicates. Statistical significance of percent survival in TSB with $35 \mathrm{mM}$ glucose was assessed using two-way ANOVA with Tukey's post-test $\left({ }^{* * *} p<0.0001\right)$. Acetate $(E)$ and acetoin $(F)$ in the supernatants of cells grown in TSB with $35 \mathrm{mM}$ glucose were measured on day 2 as described in Materials and 
Methods. Data represent mean \pm SEM in three independent biological replicates. Statistical significance was assessed by one-way ANOVA with Tukey's post-test $\left({ }^{*} p<0.05\right)$.

Figure 9. Complementation of the $\Delta r s a D$ mutant restores cell death during exposure to weak acid stress. A. Cells were grown in TSB containing $35 \mathrm{mM}$ glucose for two days, at which time they were serially diluted and plated onto TSA medium. Percent cell survival was calculated by setting day 1 as $100 \%$ survival, and then normalizing CFU values for day 2 to day $1 \mathrm{CFU}$ values. Data represent mean \pm SEM for three independent experiments. Statistical significance was assessed by one-way ANOVA with Tukey's post-test ${ }^{* * *}$ $\left.p<0.001,{ }^{* * *} p<0.0001\right)$. B. The culture supernatant $\mathrm{pH}$ values for each strain were recorded and plotted each day as indicated. C-D. Culture supernatants from the indicated strains were filtered and acetate and acetoin concentrations were determined on day two as described in Materials and Methods. Data represent mean \pm SEM in three independent experiments. Statistical significance was assessed by one-way ANOVA with Tukey's post-test ( ${ }^{* *} p<0.01$, $\left.{ }^{*} p<0.05\right)$. WT $\Omega$ voc, UAMS-1 WT strain with pLL39 vector only control; $\Delta r s a D \Omega$ voc, $\Delta r s a D$ mutant with pLL39; $\Delta r s a D \Omega \mathrm{P}_{r s a D^{-}} r s a D, \Delta r s a D$ mutant with pLL39 containing $r s a D^{+}$under the control of $\mathrm{P}_{r s a D}$. pLL39 integrates at the $\phi 11$ attachment site.

Figure 10. RsaD integrates nutritional and environmental stress signals via CodY and SigB to adapt to various niches. Under conditions that reduce CodY activity or that activate the alternative sigma factor $B(S i g B), R s a D$ abundance increases. As a result, RsaD and alsS mRNA interact via complementary base-pairing. alsS mRNA and AlsSD activity decrease, leading to acetate-mediated cell death.

\section{Tables}




\begin{tabular}{|c|c|c|}
\hline Clinical isolate & sRNAs up-regulated & sRNAs down-regulated \\
\hline Newman & 38 & 6 \\
\hline USA300 & 21 & 0 \\
\hline UAMS-1 & 16 & 2 \\
\hline
\end{tabular}




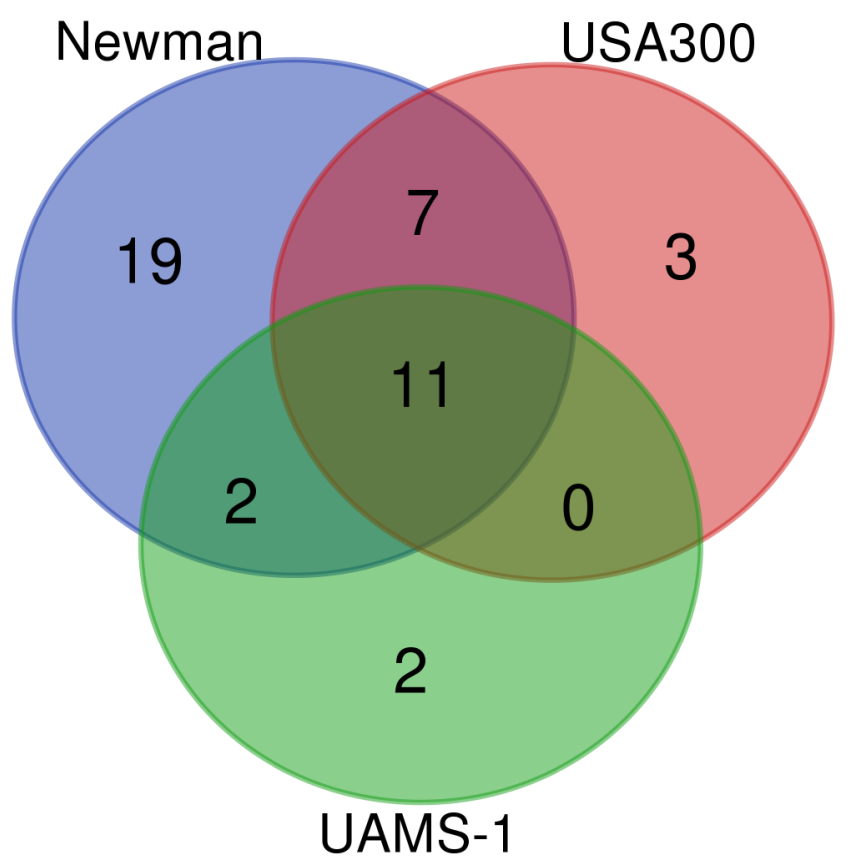

mmi_14418_f1.tif 


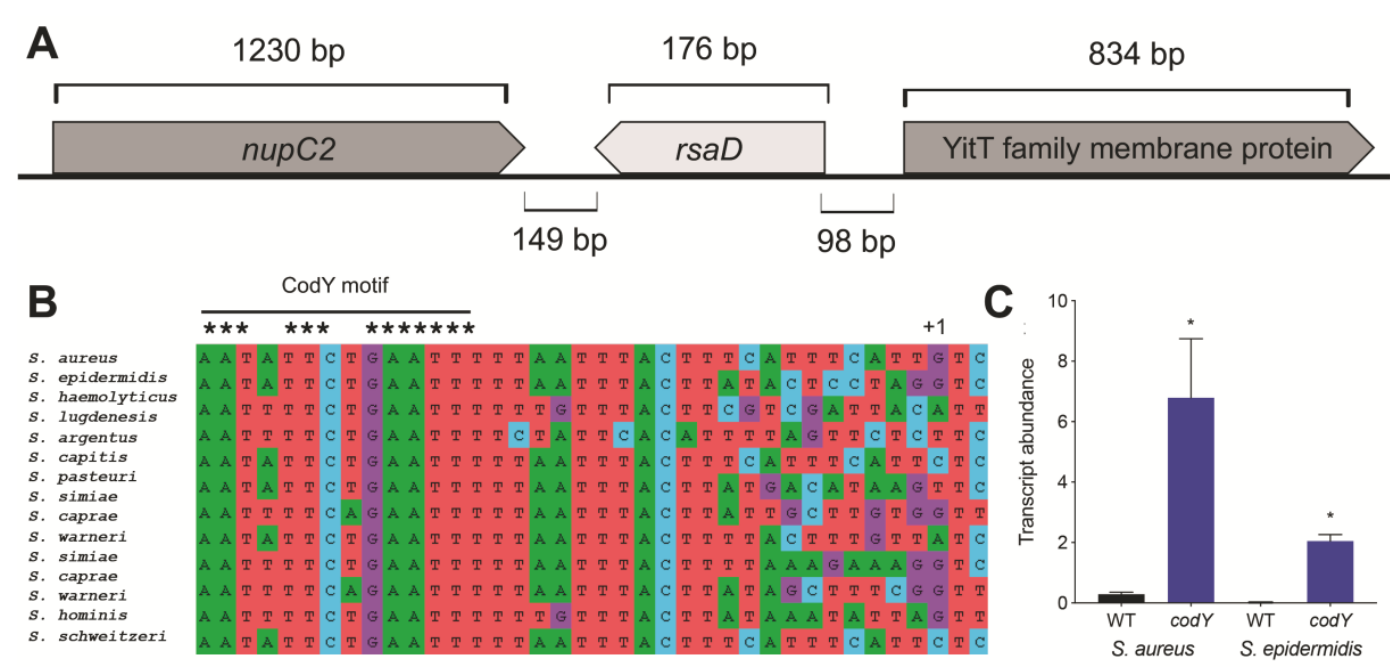

mmi_14418_f2.tif 


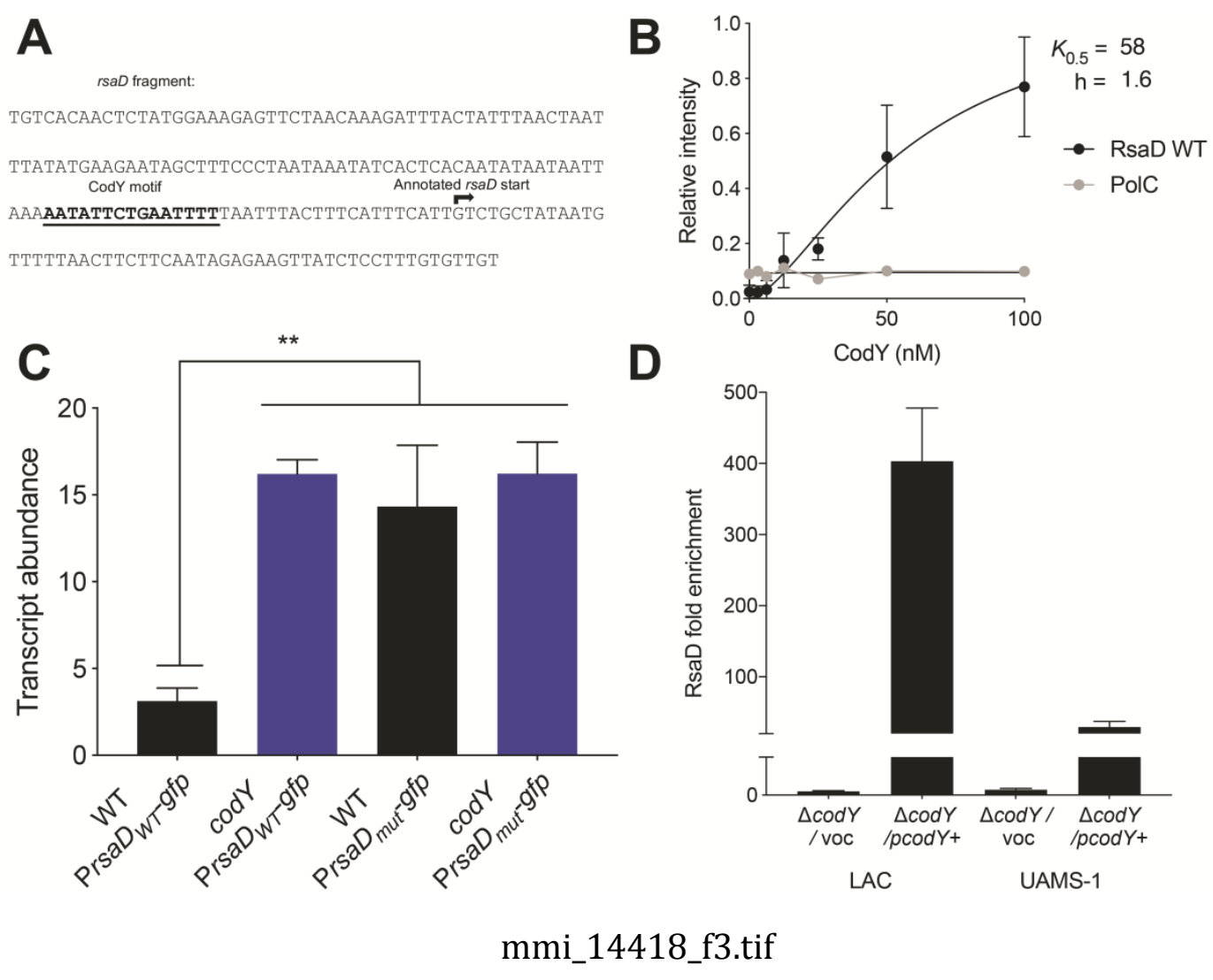




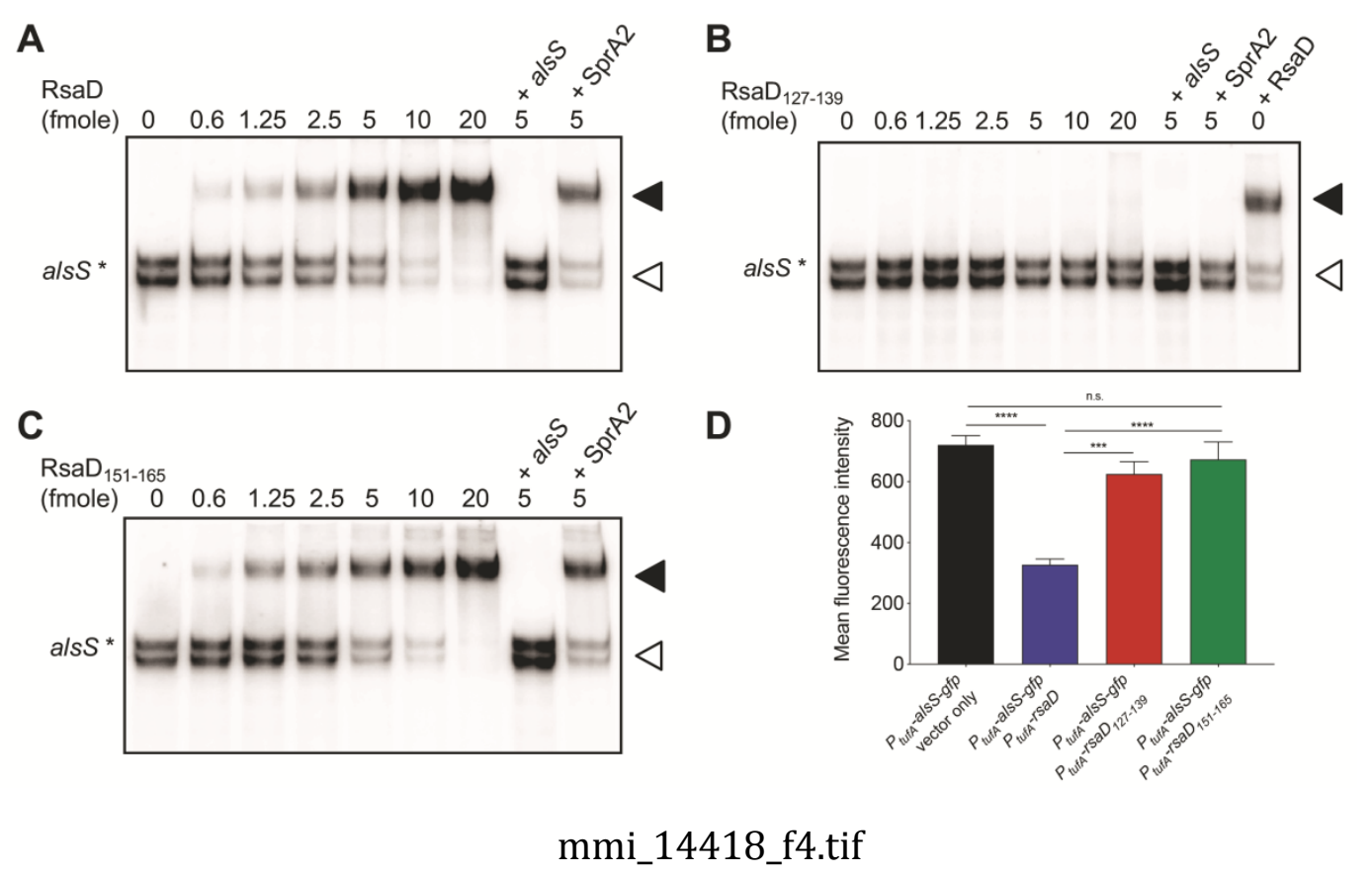




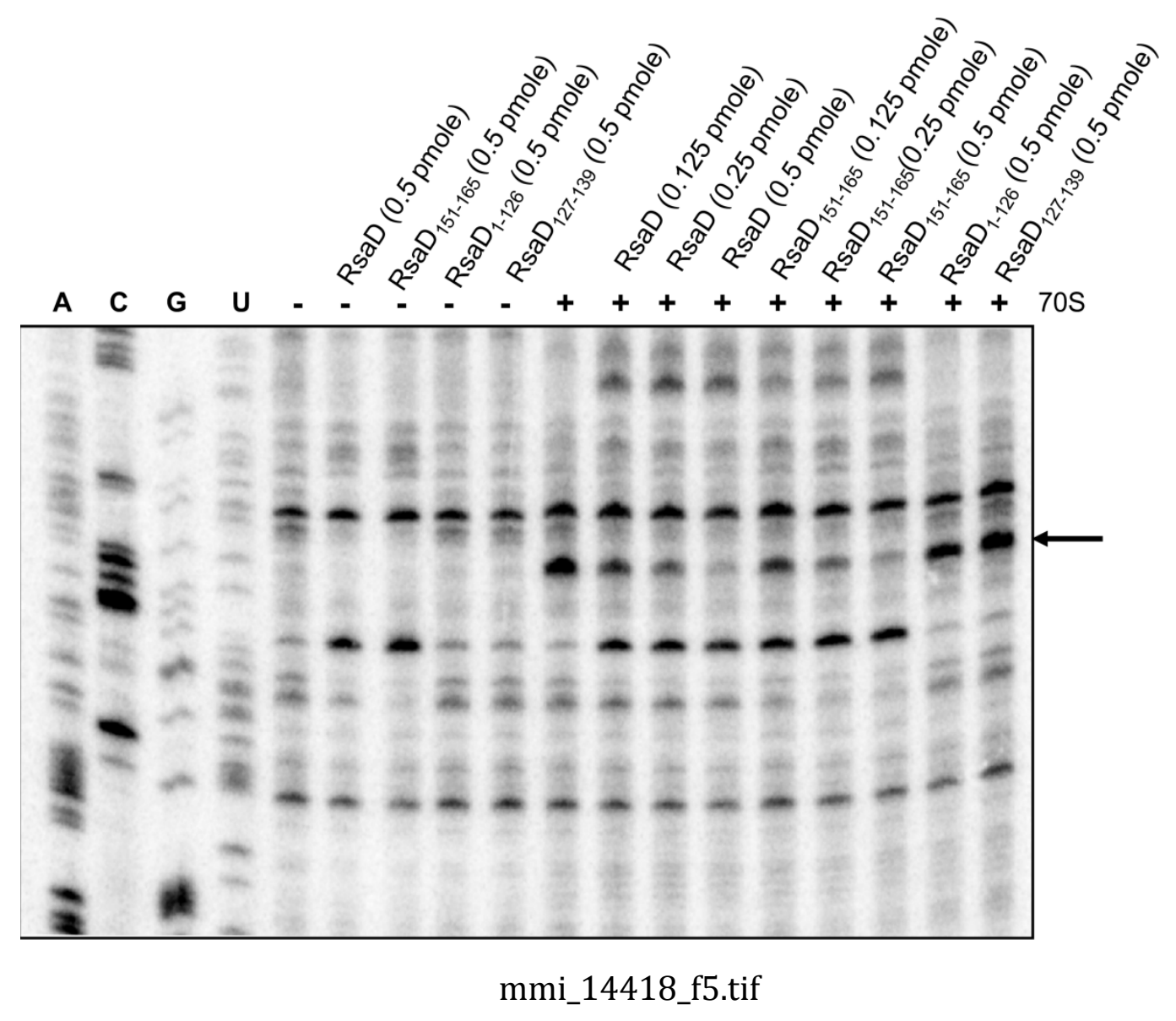



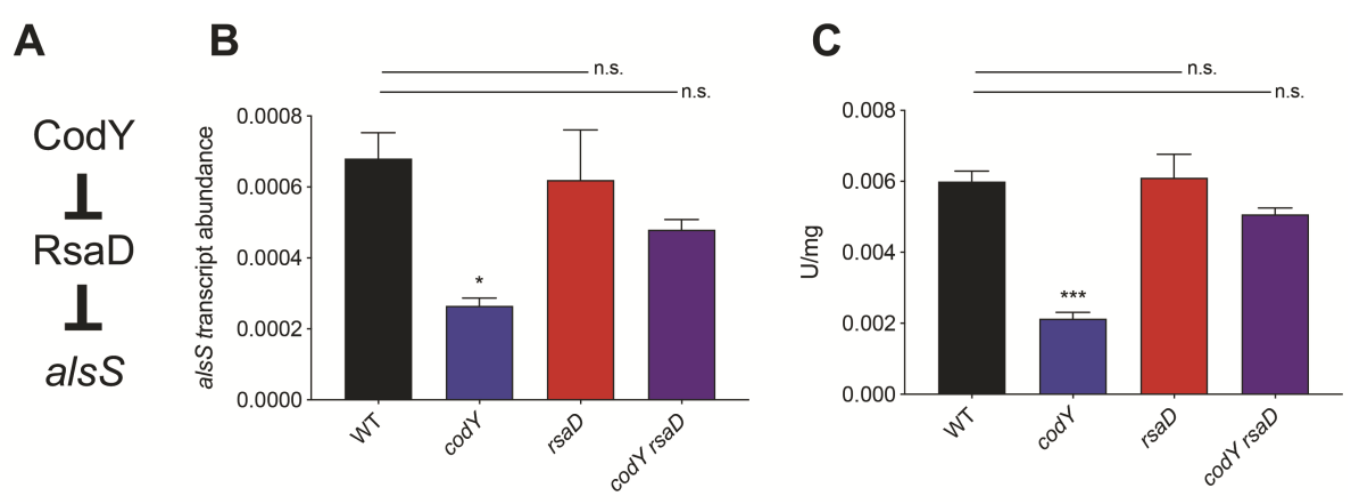

mmi_14418_f6.tif 


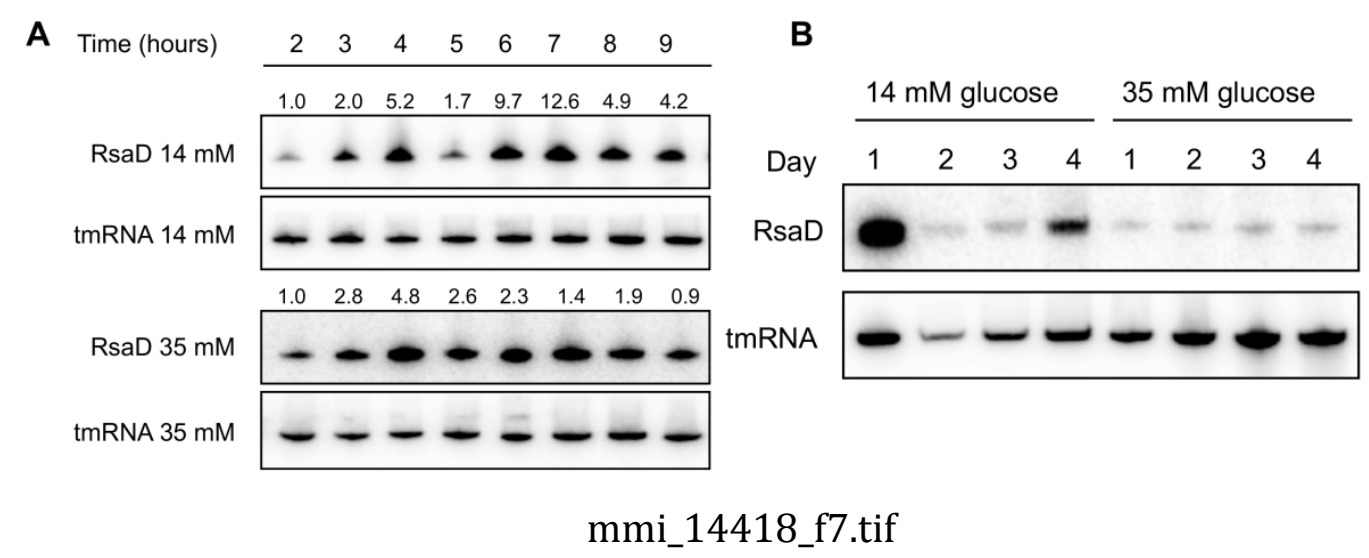



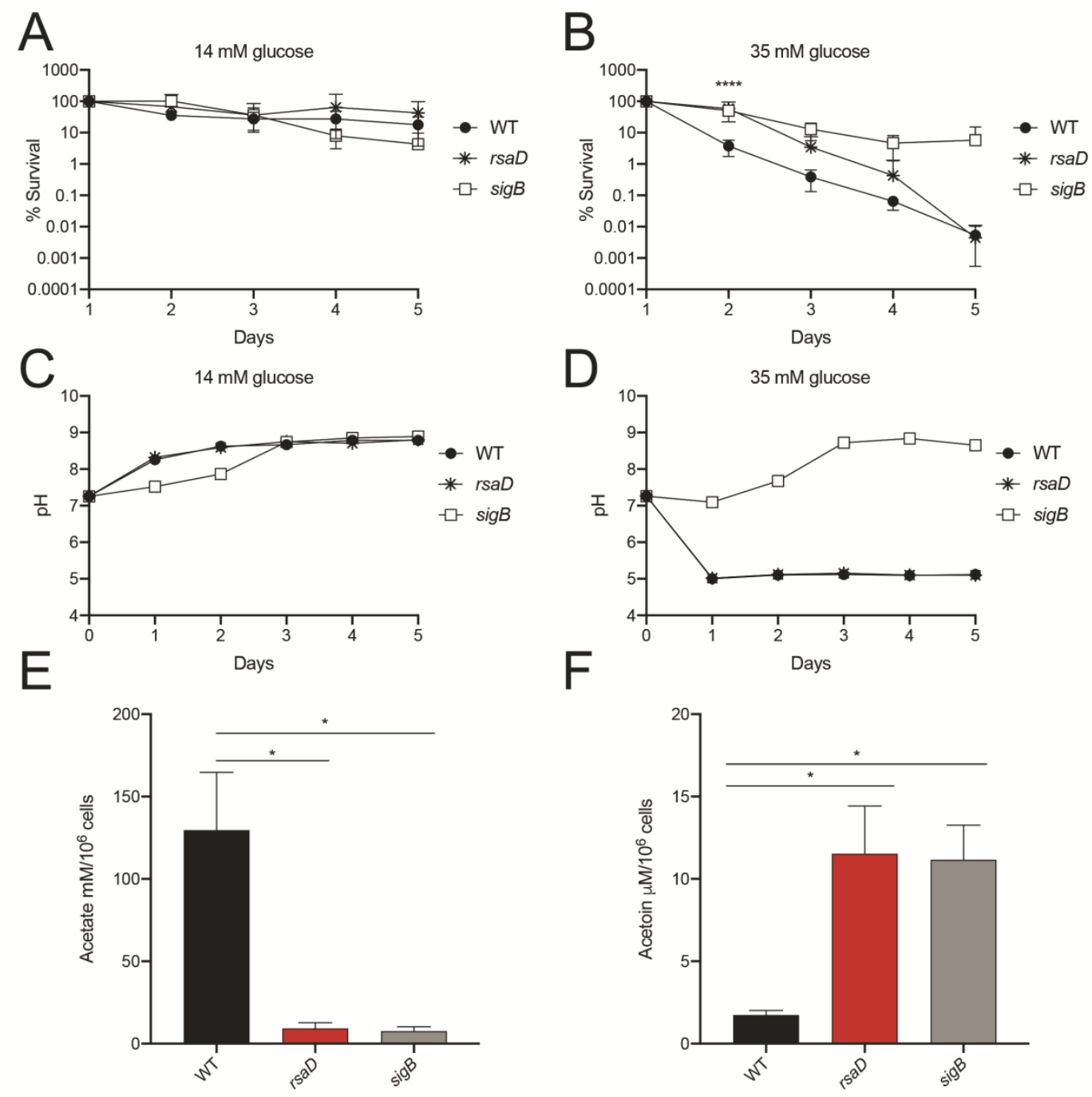

D
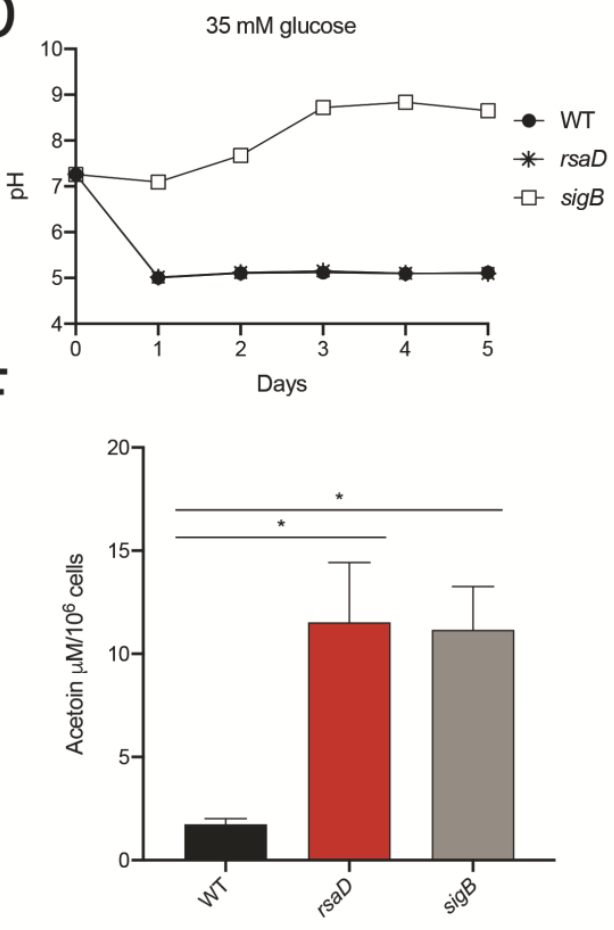

mmi_14418_f8.tif 


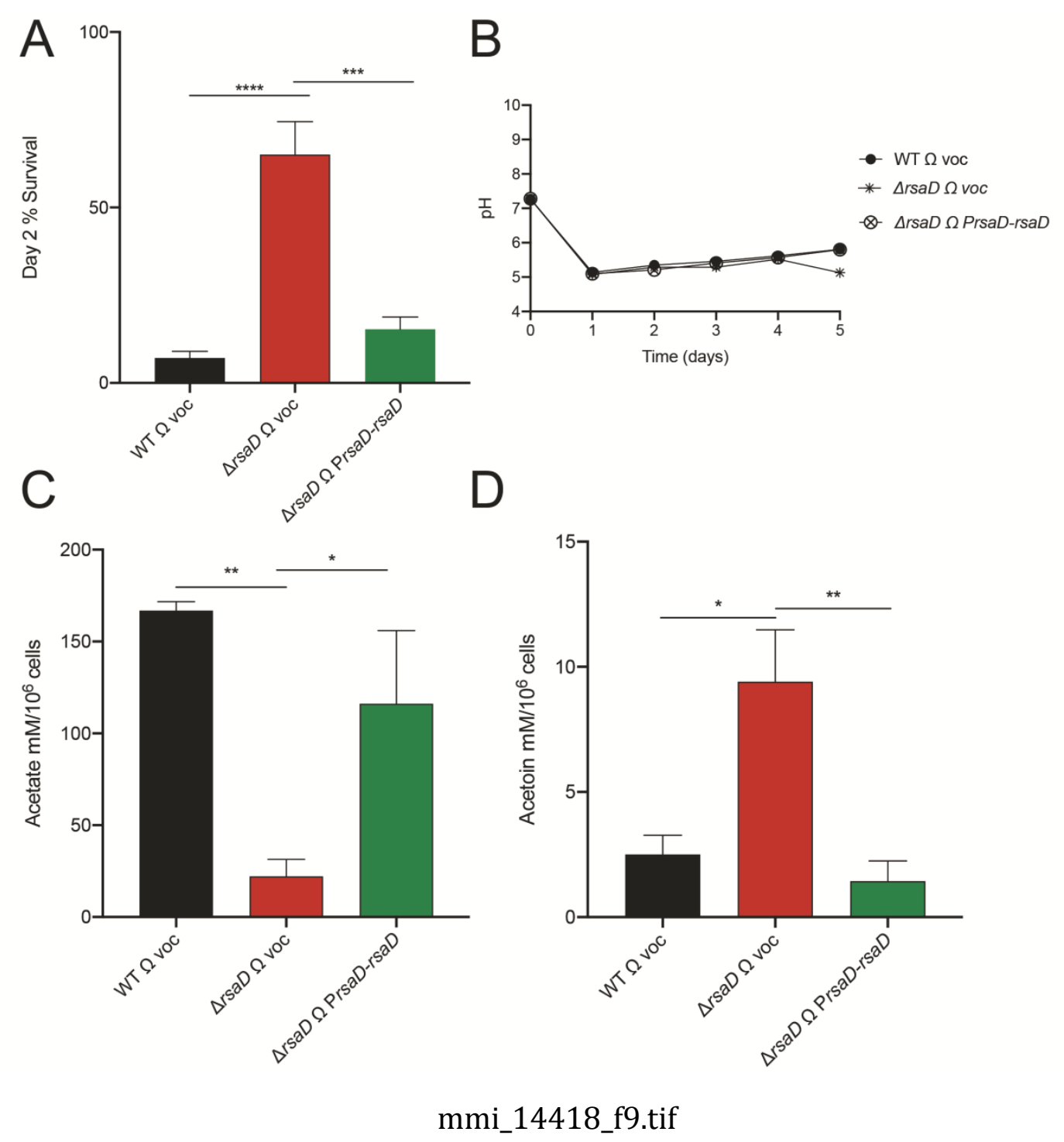




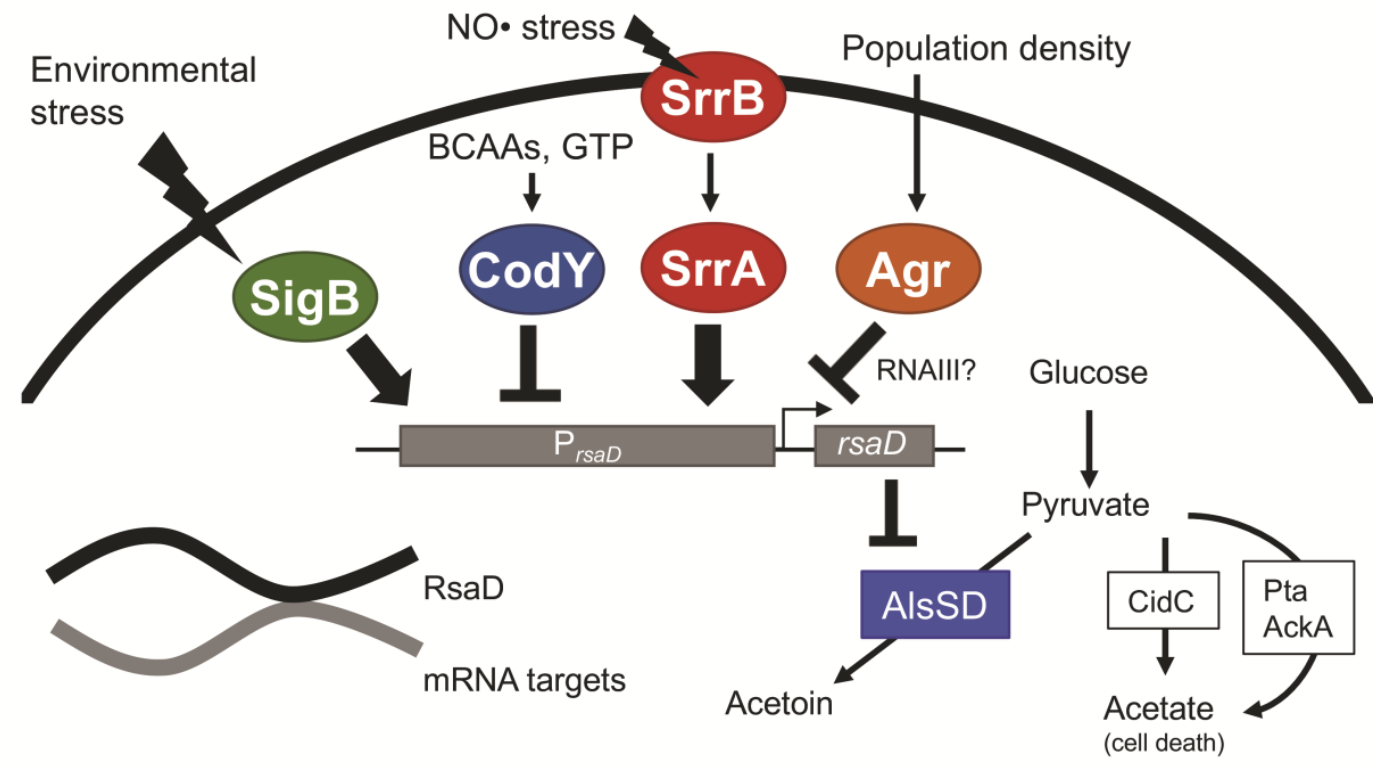

mmi_14418_f10.tif 